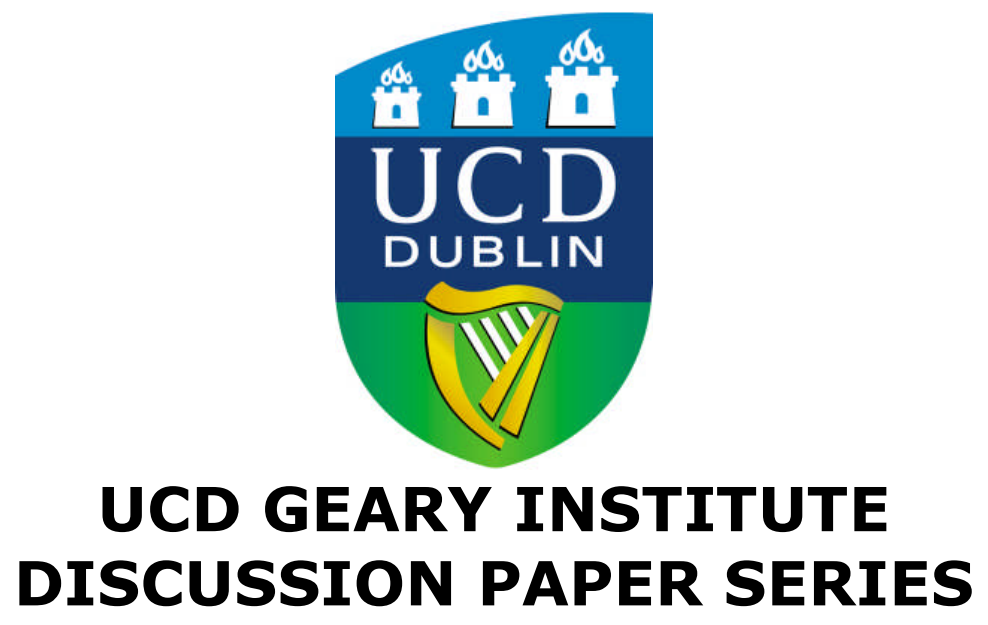

Is Employer-Based Health Insurance a Barrier to Entrepreneurship?

\author{
Robert W. Fairlie \\ Department of Economics \\ University of California, Santa Cruz and RAND \\ rfairlie@ucsc.edu
}

Kanika Kapur

School of Economics and Geary Institute

University College Dublin and RAND

Susan Gates

RAND

June 2009

We would like to thank Julie Zissimopoulos, Paul Devereux, Claude Messan Setodji, Kosali Simon, and seminar participants at UC Berkeley, RAND and the Australia National University for helpful comments and suggestions. We would also like to thank Emilie Juncker for a preliminary analysis of the data and P.J. Perez for assistance in constructing the data files. 


\title{
Is Employer-Based Health Insurance a Barrier to Entrepreneurship?
}

\begin{abstract}
The focus on employer-provided health insurance in the United States may restrict business creation. We address the limited research on the topic of "entrepreneurship lock" by using recent panel data from matched Current Population Surveys. We use difference-indifference models to estimate the interaction between having a spouse with employer-based health insurance and potential demand for health care. We find evidence of a larger negative effect of health insurance demand on the entrepreneurship probability for those without spousal coverage than for those with spousal coverage. We also take a new approach in the literature to examine the question of whether employer-based health insurance discourages entrepreneurship by exploiting the discontinuity created at age 65 through the qualification for Medicare. Using a novel procedure of identifying age in months from matched monthly CPS data, we compare the probability of business ownership among male workers in the months just before turning age 65 and in the months just after turning age 65 . We find that business ownership rates increase from just under age 65 to just over age 65, whereas we find no change in business ownership rates from just before to just after for other ages 55-75. Our estimates provide some evidence that "entrepreneurship lock" exists, which raises concerns that the bundling of health insurance and employment may create an inefficient allocation of which or when workers start businesses.
\end{abstract}

Key words: Self-employment, entrepreneurship, health insurance 


\section{Introduction}

The predominant source of health insurance in the United States for working-age adults is employer-provided health insurance. Nearly two-thirds of adults under age 65 and three-quarters of all full-time workers have health insurance through employers (U.S. Census Bureau 2007). A potential cost of this reliance on employer-provide health insurance is the non-portability of insurance across employers potentially resulting in "job lock." Workers may be reluctant to switch jobs when otherwise optimal because of the possible loss of coverage due to pre-existing condition exclusions, waiting periods on new jobs, loss of particular insurance plans, and disruption in the continuity of care with their healthcare providers.

Concerns about disruptions in health insurance coverage could also influence the decisions of individuals who are contemplating starting new businesses. Such individuals who are currently covered by employer-sponsored health insurance would eventually lose that coverage if they leave their job. Potential entrepreneurs could face high premiums in the individual health insurance market and the possibly prohibitive health costs of being uninsured. Furthermore, changes in health plans and providers may be disruptive and costly. New entrepreneurs may also be exposed to pre-existing condition limitations and waiting periods for coverage if they have a spell of uninsured unemployment between their employer-provided coverage and their new health insurance policy. ${ }^{1}$ Unless they have alternative sources of health insurance coverage, such as through a spouse's employer, this health insurance conundrum may influence their decision to start a new business.

All of these factors suggest that the U.S. focus on employer-based health insurance may restrict the formation of new businesses and create the additional inefficiency of altering who becomes and who does not become an entrepreneur. The question of whether employer-based health insurance limits business creation has important implications for the debate over health

\footnotetext{
${ }^{1}$ The 1996 Health Insurance Portability and Accountability Act (HIPAA) mandates that pre-existing condition limitations and waiting periods cannot be imposed on individuals who had continuous prior health insurance coverage, but it does not apply to individuals who do not have continuous prior coverage.
} 
care reform, which has recently regained national attention. ${ }^{2}$ There have also been calls for government action to decouple health insurance from employment directly because of this concern (Baumol, Litan and Schramm 2007), and the media is rife with reports on health insurance being the "big bump on the road to entrepreneurship" and health insurance costs "killing new-business dreams" (Egerstrom, 2007; Keen, 2005).

Promoting entrepreneurship is viewed as a national priority by governments around the world. The interest is driven primarily by evidence that small businesses create a disproportionate share of new jobs in the economy, represent an important source of innovation, increase national productivity and alleviate poverty (see Birch 1979, Reynolds 2006, and OECD 2005 for example). The self-employed are also unique in that they create jobs for themselves, representing more than ten percent of total employment in the United States and many other countries. Business ownership is the main alternative to wage/salary employment for making a living, and thus has important implications for earnings and wealth inequality. ${ }^{3}$

Given the potential consequences, it is surprising that only a handful of studies have examined whether employer-provided health insurance limits entrepreneurship. The few studies in the literature find mixed results, with some estimating that health insurance reduces transitions into self-employment by as much as 25 percent and others finding no evidence that health insurance reduces self-employment (Holtz-Eakin, Penrod and Rosen, 1996; Madrian and Lefgren, 1998; Wellington, 2001). The lack of research on the topic contrasts sharply with a much larger literature that examines the effects of employer-provided health insurance on employer-toemployer mobility (see Gruber and Madrian, 2004 for a review).

\footnotetext{
${ }^{2}$ President Obama has repeatedly promised to create a proposal that greatly expands health insurance coverage. The Council of Economic Advisors (2009) recently published a report arguing that health care reform is required to remove unnecessary barriers to job mobility.

3 Business owners are found to have higher saving rates and accumulate more wealth than wage/salary workers (Bradford 2003). Self-employed business owners hold nearly 40 percent of total U.S. wealth even though they represent less than 12 percent of the population, (Bucks, Kennickell, and Moore 2006).
} 
In this paper, we address the lack of current research on the topic of "entrepreneurship lock" by providing a new study of whether the U.S. health insurance system impedes entrepreneurial activity. We use panel data created by matching consecutive years or months of the Current Population Survey (CPS) and two identification strategies to examine this question. First, following the identification strategy pursued in most analyses of job turnover, we compare the probability of turnover of otherwise observationally equivalent employees who differ only in the value that they are likely to place on a current employer's health insurance policy. We estimate difference-in-difference models for the transition from wage-based employment to selfemployment as a function of access to alternative health insurance and family health. Individuals with no alternative means of health insurance who obtain health insurance from their own jobs, and individuals who have poor family health should be less likely to become self-employed.

The second identification strategy exploits the abrupt change in health insurance coverage occurring at age 65 due to Medicare. The discontinuity in coverage suggests that a comparison of entrepreneurship among individuals just below the age 65 cutoff to those just above the age 65 cutoff provides a test of the entrepreneurship lock hypothesis that is as close to a random experiment as possible. Although previous studies exploit the discontinuity in health insurance coverage created by Medicare (e.g. Card, Dobkin, and Maestas 2004, 2008), the approach has not been previously taken to identify the effects of health insurance coverage on entrepreneurship. The lack of research on the topic may be due to the difficulty in finding a dataset with large enough sample sizes and high-frequency measure of age. To address this problem, we use a novel procedure for identifying a person's age in months from matching monthly data from the CPS. To our knowledge, this is the first study using this procedure for identifying age in months from the CPS and the first study using the discontinuity created by Medicare to test the entrepreneurship lock hypothesis. The results from this new identification strategy and the difference-in-difference approach using recent data shed light on the question of whether employer-based health insurance restricts entrepreneurship. 


\section{Previous Literature}

The few studies that examine the relationship between entrepreneurship and an individual's health insurance coverage status find mixed results. Holtz-Eakin, Penrod and Rosen (1996) considered the effect of health insurance coverage status on transitions from employment to self-employment using the 1984-86 Survey of Income and Program Participation (SIPP) and the 1982-84 waves of the Panel Study of Income Dynamics (PSID). While their estimates were quantitatively large (a lack of health insurance portability stemming from employer-sponsored insurance reduced the probability of transition from employment to self-employment by 9 to 15 percent in the SIPP population), they were statistically insignificant. Therefore, the authors could not confirm that health insurance impeded transitions to self-employment. Madrian and Lefgren (1998) also examine this issue using the SIPP and find that by using additional waves of SIPP data (1984-93), estimates of the effect of health insurance coverage status on transitions to selfemployment attain statistical significance. In addition to using the difference-in-difference methodology used by Holtz-Eakin, Penrod and Rosen (1996), they also use the passage of continuation of coverage mandates to identify the effect of health insurance coverage status on self-employment transitions. Their estimates imply that a lack of health insurance portability accounts for a 25 percent reduction in transitions to self-employment. In other work, Wellington (2001) uses a similar estimation methodology to analyze data from the 1993 Current Population Survey. The author estimates the impact of having health insurance through one's spouse on the likelihood of self-employment. Her estimates suggest that a guaranteed alternative source of health insurance would increase the probability of self-employment between 2.3 and 4.4 percentage points for husbands and 1.2 and 4.6 percentage points for wives.

Another potential source of variation in the health insurance market for the self-employed comes from the tax treatment of health insurance. The tax subsidy to health insurance for the self employed, introduced at $25 \%$ in 1986 rose to $100 \%$ by 2003 in a number of discrete changes. 
Velamuri (2005) uses this variation and compares the female self-employment rate in 1984-85 to that in 1990-91 and finds that women with no spousal health insurance were substantially more likely (12 to $25 \%$ ) to be self-employed when tax subsides were higher compared to women who had access to spouse health insurance. However, estimates based on transitions to selfemployment were statistically insignificant. Gumus and Regan (2008) present the raw percentages of workers transitioning into self employment between 1995 and 2005 and find that the transition rate has been stable over time and does not show any evidence of increasing when tax credits were increased. They also find no relationship between tax-deductibility and rates of health insurance coverage among the self-employed. The relatively small estimates obtained by the studies using the variation provided by tax subsidies may be driven by the fact that many small businesses have very low levels of sales and profits in the first few years of existence (U.S. Census Bureau 1997), and thus are not eligible for or benefit only slightly from the tax credit.

DeCicca (2007) presents additional evidence on the effect of legislative changes on transitions to self employment. The study focuses on the effect of New Jersey's 1993 Individual Health Coverage Plan that included an extensive set of reforms facilitating access to coverage that was not employer-linked. The results suggest that New Jersey's plan increased self-employment among New Jersey residents by about 15 to 25 percent - a large effect compared to the estimates obtained using the Tax Reform Act. On net, there appears to be little consensus in this literature on the existence or magnitude of the effect of health insurance on entrepreneurship. ${ }^{4}$

In this study, we use recent panel data created by matching consecutive years or months of the CPS to estimate the effect of health insurance coverage status on business creation. Existing prior research on this topic uses data from the 1980s and early 1990s, and many important changes have occurred in the health insurance market and in the labor market for

\footnotetext{
${ }^{4}$ The literature on the effects of health insurance coverage on job mobility among wage/salary workers also finds mixed results. See Stroupe et al. (2001), Okunade and Wunnave (2002), Bradley et al., (2005), Sanz de Galdeano (2006) and Gilleskie and Lutz (2002) for a few recent examples, and Gruber and Madrian (2004) for a recent review.
} 
entrepreneurs. In particular, health insurance costs have risen dramatically since the 1990s, particularly for small group and individual plans. The demographic composition of new entrepreneurs has also changed, with the near-elderly -- a rapid-growing segment of the U.S. population and one that faces higher costs for individual health insurance plans -- becoming more likely to consider business ownership (Zissimopoulos and Karoly, 2007). In the last few years, however, the advent of consumer-directed health plans and Health Reimbursement Accounts under Section 105 have opened up avenues for the self-employed to obtain health insurance at potentially lower costs. In addition, a number of state and federal initiatives such as the Health Insurance Portability and Accountability Act, and state individual health insurance reforms increasing tax deductibility for self-employed insurance plans have been passed. These initiatives may have improved access to health insurance for self-employed individuals. To address these concerns a current examination of the role of health insurance in entrepreneurship is needed.

\section{Conceptual Framework}

Access to health insurance is a major concern among entrepreneurs. In a recent survey, health insurance costs were most frequently listed as the most critical problem faced by small businesses (National Federation of Independent Business, 2008). In a related survey, threequarters of the self-employed listed cost as an important barrier to offering health insurance through their business and 78\% rated the satisfaction with their premium costs as "low" (AWP, 2005). Furthermore, the burden of premium costs is disproportionately high on the smallest establishments - representing $5.7 \%$ of sales for solo practitioners compared to $2.8 \%$ for larger establishments (AWP, 2005).

Self-employed individuals who do not have alternative access to health insurance, such as through a spouse, may need to rely on the individual health insurance market. Premiums in the individual health insurance market can be very high. In 2005, the average annual premium for all single policies was $\$ 2,835$ and for all family policies was $\$ 5,568$. These average premiums mask 
substantial variation across individuals. Notably, average premiums are substantially higher for older people ( $\$ 4,288$ for single policies ages $55-64$ and $\$ 6,835$ for family policies ages $45-64$ ) (Bernard and Banthin 2008). It is also important to note that these averages are based on information from people who actually purchased policies in the individual market.

In this section we provide a formal conceptual framework to describe why the market for health insurance, as it currently exists in the U.S., might be a barrier to entrepreneurship. This framework provides a background for the empirical analysis that follows. This discussion is adapted from a model presented in Gruber and Madrian (2004).

We assume that all employer-sponsored group health insurance coverage is the same (health insurance is a homogenous good) and individuals either have it or they do not. Individuals have preferences over wage compensation (or the monetary return from selfemployment) and employer-sponsored group health insurance.

A worker's utility can be described by $\mathrm{U}_{\mathrm{ij}}=\mathrm{U}\left(\mathrm{W}_{\mathrm{ij}}, \mathrm{H}_{\mathrm{ij}}\right)$, where $\mathrm{U}_{\mathrm{ij}}$ is the utility of worker $\mathrm{i}$ at firm $\mathrm{j} . \mathrm{W}_{\mathrm{ij}}$ is the wage of worker $\mathrm{i}$ at firm $\mathrm{j}$, and $\mathrm{H}_{\mathrm{ij}}$ is a binary indicator of employer-sponsored health insurance coverage of worker i at firm $\mathrm{j}$. Let $\Delta \mathrm{W}_{\mathrm{ij}}$ denote the compensating wage differential in firms offering health insurance reflecting the fact that if individuals value health insurance, they will accept a lower wage from an employer that offers health insurance. Firms face a cost, $\mathrm{C}_{\mathrm{ij}}$, of providing workers with health insurance. If self-employed individuals and firms could purchase insurance on a per-worker basis and this insurance was perfectly experience rated and wages were perfectly flexible, the compensating differential $\Delta \mathrm{W}_{\mathrm{ij}}$ would be equal to the cost of health insurance $C_{i}$. In this highly stylized model, health insurance would have no effect on the labor market equilibrium since self-employed individuals could purchase health insurance for the same cost as other employers. Workers pay the same compensating differential if they choose a job with insurance and as a result, they select a job or self-employment where they have the highest marginal product of labor. So, workers will switch from a job (j) with group 
employer-provided health insurance to self employment (s) with no group health insurance if $\mathrm{U}\left(\mathrm{W}_{\mathrm{ij}}-\Delta \mathrm{W}, 1\right)<\mathrm{U}\left(\mathrm{W}_{\mathrm{is}}, 0\right)$. Self-employed workers can then choose to purchase non-group coverage for a cost of $\mathrm{C}_{\mathrm{i}}$ in the individual market. In this stylized model, wage earners who do not have employer-sponsored health insurance will transition to self-employment based on a simple comparison of their marginal productivity in the two sectors, and therefore should be as likely to move into self-employment than wage earners who have group health insurance.

This stylized model is not realistic in several ways. First, the self-employed face higher health insurance costs than large firms because of their inability to capitalize on economies of scale, higher administrative costs per person, and lower bargaining power with insurers. ${ }^{5} \mathrm{~A}$ compensating wage differential could adjust for this factor (i.e. people would enter self employment only if the expected wage was higher in that sector), but it would still lead to distortions because some people have access to group health insurance (i.e. through a spouse's employer) while others do not. Second, employers cannot fully vary health insurance coverage and wages in accordance with each worker's insurance costs. Therefore, workers with high health costs may be paying far less than the true costs of their insurance under group insurance. This can lead to distortions because workers with high health costs will be less likely to leave to start businesses even if otherwise optimal. Finally, health insurance is not a homogenous good that can seamlessly be transferred from an employer to self-employment. Despite the HIPAA protections noted above, individuals may incur disruptions in their relationships with providers and changes in policy quality as a result of purchasing new insurance under self-employment. These aspects of the market for health insurance can lead to distortions in the level of entrepreneurship, who becomes an entrepreneur and the timing of entry into self-employment.

Using the framework described earlier, even if an individual was less productive in job, $\mathrm{j}$, with group health insurance than when self employed $\left(\mathrm{W}_{\mathrm{ij}}<\mathrm{W}_{\mathrm{is}}\right)$, the individual may not choose self employment if $\mathrm{U}\left(\mathrm{W}_{\mathrm{ij}}-\Delta \mathrm{W}, 1\right)-\mathrm{U}\left(\mathrm{W}_{\mathrm{is}}, 0\right)>0$. In this case, the cost of forgoing group health

\footnotetext{
${ }^{5}$ http://www.rwjf.org/pr/synthesis/reports_and_briefs/pdf/no2_policybrief.pdf
} 
insurance coverage outweighs the additional utility from higher wages under self-employment. Even though the individual can use the higher wages from self-employment to purchase individual insurance, this insurance is likely to have a substantially higher cost in the individual market, have lower quality, and/or pose a disruption in the continuity of care for the worker. We expect that wage earners for whom $\mathrm{U}\left(\mathrm{W}_{\mathrm{ij}}-\Delta \mathrm{W}, 1\right)-\mathrm{U}\left(\mathrm{W}_{\mathrm{is}}, 0\right)$ is large will be less likely to move into self employment. This difference in utilities represents the value of group employer-provided health insurance relative to self-employment. This value will be lower for workers who have access to another source of health insurance (spouse, parent, government program) and it would also be lower for workers that would face relatively low insurance costs in the market for individual health insurance (young, healthy workers with few dependents). The end result is that some individuals may be dissuaded from starting businesses when it is otherwise optimal because of the link between health insurance and employment.

\section{Data}

We use data from the 1996 to 2006 Annual Demographic and Income Surveys (March) of the CPS. Each annual survey, conducted by the U.S. Census Bureau and the Bureau of Labor Statistics, is representative of the entire U.S. population and interviews approximately 50,000 households and more than 130,000 people. Although the CPS is primarily used as a crosssectional dataset offering a point-in-time snapshot, it is becoming increasingly common to follow individuals for two consecutive years by linking surveys. Households in the CPS are interviewed each month over a four-month period. Eight months later they are re-interviewed in each month of a second four-month period. The rotation pattern of the CPS makes it possible to match information on individuals in March of one year who are in their first four-month rotation period to information from March of the following year, which represents their second four-month rotation period. This creates a one-year panel for up to half of all respondents in the first survey. To match the March CPS files from 1996 to 2006, we use the method discussed in Fairlie and 
London (2008). The supplemental samples to the 2001 to 2006 ADFs, which are generally not re-interviewed in the following March, are removed.

The main advantage of the matched CPS is the large sample size. The matched CPS sample that we use includes more than 160,000 observations for wage and salary workers in the first survey year. The sample includes 5,100 transitions into self-employment, which is considerably larger than the other panel datasets such as SIPP and PSID. In their study of health insurance and entrepreneurship, Holtz-Eakin, Penrod, and Rosen (1996) report 700 transitions from the wage and salary sector to self-employment in their sample from SIPP and considerably less in the PSID.

Across, the 1996-2006 CPS surveys, we find that roughly 75 percent of CPS respondents in one survey can be identified in the subsequent year's survey. The main reason that match rates are less than 100 percent is because of the movement of individuals or households out of sampled dwelling units. The CPS does not follow individuals who move out of CPS sampled dwelling units in future months. Another problem is due to false positive matches. Although unique household and person identifiers are available in the CPS to match non-moving individuals over time, false matches occur because of miscoding. We use a procedure that compares the sex, race and age of the person in each March file to remove false matches. Any changes in coding are identified as false matches. ${ }^{6}$ False match rates, however, are very low (roughly 3 percent) and do not vary substantially across years.

The loss of observations due to household movement raises concerns about the representativeness of the matched CPS sample. We investigate this issue further by conducting a comparison of mean values from the original cross-sectional CPS sample to means values from the matched CPS sample. As expected, we find that the matched sample has higher insurance, employment and marriage rates, and is more educated and older. The matched sample is also less likely to be a minority, live in the central city and receive public assistance. But, in all of these

\footnotetext{
${ }^{6}$ Age in the second survey year is allowed to be in the range from -1 to +3 from the first survey year.
} 
cases the differences are very small. For example, health insurance coverage rates are only 3 percent different and the matched sample is only one year older than the original sample (see Fairlie and London 2008 for more details).

\section{CPS HEALTH INSURANCE MEASURE}

The CPS health insurance questions asks individuals to report all sources of health insurance coverage during the entire year prior to survey month. ${ }^{7}$ However, comparisons of CPS estimates of health insurance coverage to other surveys that ask about insurance at the time of the survey reveal similar numbers. Estimates from the SIPP, MEPS and National Health Interview Survey (NHIS) indicate that roughly 40 million individuals were uninsured at the time of the survey in 1998 (CBO, 2003). CPS estimates for the number of individuals with no insurance for the entire year were also roughly 40 million in that year, suggesting that the CPS overstates the number of individuals who are uninsured for an entire year. Bhandari (2004) finds similar estimates of insurance coverage rates in the CPS and point-in-time estimates from the SIPP even within several demographic groups. Estimates from the SIPP and MEPS indicate the number of people who are uninsured for an entire year is between 21 and 31 million. Thus, CPS respondents may be underreporting health insurance coverage over the previous calendar year because of recall bias or because they simply report their current coverage (see Bennefield 1996; Swartz 1986; CBO 2003; and Bhandari 2004 for further discussion). Even if the CPS estimates capture a point-in-time measure of health insurance coverage, the measure of health insurance status does not change from year to year and thus allows for an analysis of transitions in status.

\section{Health Insurance Coverage and Self-Employment}

\footnotetext{
${ }^{7}$ The CPS asks separate questions about employer-provided (own and dependent), privately purchased, military, Medicaid, Medicare, Indian Health Service, and other sources of health insurance
} 
Table 1 provides a descriptive profile of the variation in health insurance coverage by employment status. ${ }^{8}$ We find that the self-employed are nearly twice as likely to be uninsured than wage/salary workers. Roughly $20 \%$ of self employed men and women report no insurance compared to $11.8 \%$ of male wage/salary workers and $10.5 \%$ of female wage/salary workers. The uninsured rates for the self-employed are also higher than those for the other/not working population. Although this group includes the unemployed, not in the labor force and low hours workers, health insurance rates are 6.8 percentage points higher than rates for the self-employed for men and 4.5 percentage points higher for women.

Insured self-employed men are most likely to get their coverage from employment (33\%), followed by dependent employer coverage (21\%) and individual coverage (21\%). However, insured self-employed women are most likely to get dependent employer coverage (35\%), followed by individual coverage (22\%) and coverage from own employment (19\%). The distinction between individual coverage and own employer coverage for the self-employed is nebulous. Self-employed individuals may obtain health insurance only for themselves, but purchase it through their business, and report this coverage as employment-based insurance rather than individual insurance.

The lack of health insurance among full-time, full-year self-employed business owners is similarly high. ${ }^{9}$ Slightly more than $20 \%$ of full-time, self-employed men are uninsured and $19.7 \%$ of full-time, self-employed women are uninsured. These rates of uninsurance are considerably higher than for full-time, wage/salary workers.

In table 2, we use the two-year panel structure of our data to examine health insurance types and coverage in the second year for the newly self-employed, self-employment leavers, and the self-employed in both survey years. These estimates provide further evidence on the strong relationship between self-employment and not having health insurance. Individuals who are

\footnotetext{
${ }^{8}$ Self-employment, hours worked, weeks worked and income are measured for the last calendar year to correspond to the health insurance variable.

${ }^{9}$ Full-time workers work 35 or more hours per week and 40 or more weeks a year.
} 
newly self-employed have very high rates of uninsurance -- 24.5 percent for men and 23.2 percent for women -- indicating that initial movement to self-employment is strongly associated with the loss of health insurance. As reported in Table 1, both wage/salary workers and those not working had substantially lower rates of uninsurance. ${ }^{10}$

Although individuals who have been self-employed for at least two consecutive years have higher rates of health insurance coverage than the newly self-employed, coverage rates remain very low. Among men, $18.6 \%$ lack health insurance, and $17.4 \%$ of women are uninsured. Another interesting finding is that more than half of the male workers who leave self-employment move to jobs that have employer-provided health insurance. A large percentage of women leaving self-employment also move to jobs with employer-provided insurance. Overall, these results suggest that being uninsured is associated with movements to and from self-employment. Four percent of all male wage/salary workers start a business each year (see Table 3). For those who have health insurance coverage from their employer, business creation rates are substantially lower at $2.9 \%$. In contrast, $6.6 \%$ of workers who have health insurance coverage from a spouse start a business. Wage/salary workers who have no insurance coverage have a similarly high likelihood of starting a business. This result is not being driven by the unemployed or low-hours workers because only wage/salary workers with 20 or more weeks and 15 or more hours per week are included in the sample. Furthermore, when we condition on full-time, fullyear work we find similar results. Business creation rates are substantially lower among wage/salary workers who have employer insurance than among wage/salary workers who have insurance coverage through a spouse or do not have insurance.

Although business entry rates are lower for women, similar patterns across health insurance coverage emerge. Entrepreneurship rates are much lower for female workers with

\footnotetext{
${ }^{10}$ Over half of the uninsured newly self-employed were insured before becoming self-employed, and for these workers the move to self-employment concurred with a loss of health insurance.
} 
employer insurance than for female workers with spousal coverage or no insurance. Conditioning on full-time work does not change this conclusion.

Of course, we cannot interpret these descriptive results as evidence that employer health insurance is an impediment to self-employment, since employer health insurance is correlated with job quality. Workers who have employer-provided health insurance may be less likely to move to self-employment or another job simply because they already have a job with a good compensation package. We attempt to address these concerns in the next section.

\section{Estimating the Effects of Health Insurance Coverage Status on Entrepreneurship}

We use two main estimation strategies to identify the effect of health insurance coverage status on entrepreneurship. First, we construct difference-in-difference models of the transition to self-employment from wage-based employment as a function of access to alternative health insurance and family health. Individuals with no alternative means of health insurance who obtain health insurance from their own jobs, and individuals who have poor family health should be less likely to become self-employed, all else equal. The second identification strategy that we use takes advantage of the abrupt change in health insurance coverage occurring at age 65 due to Medicare. We explore whether the gain in health insurance at age 65 encourages individuals to become self-employed business owners by comparing rates of self-employment among those just below age 65 with rates among those just above age 65 . We describe each of the estimation methodologies in turn.

\section{DIFFERENCE-IN-DIFFERENCE ESTIMATES}

To identify the effect of health insurance coverage status on entrepreneurship, we compare the rate of entrepreneurial entry for an experimental group that potentially faces a disruption in health insurance coverage to the rate of entry for a control group that does not face a disruption. In addition, we also use the fact that groups with a high demand for their current 
health insurance policy should be less likely to leave their jobs to start a business. The literature has used several different variables to proxy for high demand including number and health status of family members (Holtz-Eakin, Penrod and Rosen 1996, Gruber and Madrian 2004). We focus on a few of these measures that are available in the CPS and best capture potential demand for health insurance and care. The measures of potential health care demand that we include are the following: (i) having a family member in bad health, (ii) number of family members in bad health, and (iii) lacking an alternative source of health insurance coverage through a spouse's employer plan. ${ }^{11}$ These measures of family bad health do not include the health status of the respondent. Individuals who have a family member in poor health are likely to have a high demand for their current employer-provided health insurance policy since they may face high premiums in the individual health insurance market or a discontinuity in their treatment if they change insurance plans. ${ }^{12}$ Workers who have only a single source of employer-provided health insurance are likely to have a higher demand for this health insurance compared to workers who have access to an alternative source of health insurance from a spouse's employer-provided health insurance plan. ${ }^{13}$

While there is considerable flexibility in the choice of experimental and control groups in a difference-in-difference estimator, the comparability of the two groups is important to obtain a consistent estimator. The key assumption, which is likely to hold only if the groups are comparable, is that the effect of any exogenous influences is the same on the control and the experimental groups (Meyer 1995). We use two main classifications of experimental and control groups. First, we define individuals who hold employer-provided health insurance as the

\footnotetext{
${ }^{11} \mathrm{Bad}$ or poor health is defined by individuals reporting that their health is "fair" or "poor" instead of "good," "very good," or "excellent." Spousal coverage is measured by using household, family and spouse identifiers for matching spouses, and information from each individual's employer health insurance coverage.

${ }^{12}$ Less direct measures of potential health demand include pregnancy and the total number of family members. Pregnancy is associated with additional labor supply changes, and the total number of family members is less precise that the number of family members in bad health.

${ }^{13} \mathrm{We}$ also use spouse's employer-provided health insurance coverage or non-coverage to identify the control and experimental groups, respectively, as discussed below.
} 
experimental group and individuals who do not hold employer-provided health insurance as the control group. By definition, individuals who hold health insurance are more likely to be deterred from moving to self employment because of their current health insurance status than individuals who do not hold health insurance. Empirically, we estimate the following probit model:

\section{1 $\operatorname{Prob}\left(\mathrm{y}_{\mathrm{i}}\right)=\Phi\left(\beta_{0}+\beta_{1} \mathrm{H}_{\mathrm{i}}+\beta_{2} \mathrm{D}_{\mathrm{i}}+\delta_{3} \mathrm{H}_{\mathrm{i}} \mathrm{D}_{\mathrm{i}}+\gamma^{\prime} \mathrm{X}_{\mathrm{i}}\right)$,}

where $\mathrm{H}_{\mathrm{i}}$ denotes whether an individual holds employer-provided health insurance, $\mathrm{D}_{\mathrm{i}}$ is potential health care demand, and $\mathrm{X}_{\mathrm{i}}$ is a vector of demographic controls. ${ }^{14}$ We estimate separate models for men and for women. The sample consists of wage and salaried workers in the baseline year (t). The dependent variable, $\mathrm{y}_{\mathrm{i}}$, equals 1 if the worker moves to self-employment in the following year $(t+1)$. We estimate several versions of this model with the measures of potential health care demand discussed above. The coefficient on the interaction between health insurance and potential health care demand, $\beta_{3}$, captures the difference-in-difference estimate of the entrepreneurship-lock. ${ }^{15}$ A negative coefficient is consistent with the notion that current employer-provided health insurance is a disincentive to entrepreneurship, and suggests that those individuals who would face a disruption in their health insurance and have a high demand for health care are relatively less likely to move into self-employment than individuals who have a low demand for health care. Note that we cannot simply interpret $\beta_{1}$ as the estimate of the effect of employer-provided health insurance on entrepreneurship because having own employerprovided health insurance may be correlated with high quality jobs and therefore this estimate would be biased.

\footnotetext{
${ }^{14}$ In $\mathrm{X}_{\mathrm{i}}$, we include control variables for the individual's job in the baseline year, family, individual demographics, residence, and survey year.

${ }^{15}$ The marginal effects for interaction terms in a probit model may be biased (Ai and Norton, 2003). Results in the paper are very similar using a linear probability model. In addition, we have calculated predictions of the marginal effects and their distribution and found a similar pattern of results, although these are somewhat more cumbersome to report.
} 
A potential problem with this classification of experimental and control groups is that individuals who hold employer-provided health insurance differ from those who do not (Kapur 1998). Insurance holders have higher wages, longer tenure, and more education than nonholders. ${ }^{16}$ In additional specifications, we restrict the sample to individuals who hold employerprovided health insurance to improve the comparability of the experimental and control groups. We define the control group as individuals who have access to alternative health insurance from a spouse's employer. We do not require that the individual is covered by the spouse's plan, only that the spouse has own employer-provided health insurance, since individuals can usually obtain coverage from a spouse's employer even if they are not currently covered by the policy. ${ }^{17}$ The experimental group is defined as individuals who do not have access to spouse employerprovided health insurance. Individuals who do not have access to an alternative plan should be more likely to be deterred from moving to self-employment because of health insurance. Workers without spousal coverage face a potential disruption in health insurance coverage when moving from wage/salary work to self-employment, whereas workers with spousal coverage potentially do not face a potential disruption in health insurance. Individuals in these two groups are relatively similar across several dimensions such as wages, education, and tenure, suggesting that individuals with own and spousal employer-provided health insure form a more comparable control group for individuals with only employer-provided health insurance. ${ }^{18}$

We estimate the following probit model on the sample of individuals who hold employerprovided health insurance.

\footnotetext{
${ }^{16}$ In our data, insurance holders are paid $\$ 25$ per hour and $35 \%$ have college degrees compared to nonholders who are paid $\$ 18$ per hour and $20 \%$ have college degrees. Among insurance holders, those who have spouse health insurance are very similar to those who do not have it - both groups are paid $\$ 25$ per hour. Thirty-seven percent of those with both own and spouse insurance have college degrees compared to $34 \%$ of those with only own health insurance. Among those who have employer-provided health insurance, individuals with spouse health insurance have similar demographic characteristics, such as age and race, compared to those who do not have spouse health insurance. In contrast, employer-provided health insurance holders are older and more likely to be white compared to non-holders.

${ }^{17}$ We do not have information on whether the individual was offered health insurance and turned it down. ${ }^{18}$ Individuals who have both employer-provided health insurance and access to spouse health insurance may still have a preference for their own employer policy, and as a result, prefer to stay in their current job. This would result in an under-estimate of the effect of health insurance on self-employment transitions.
} 
where $\mathrm{NS}_{\mathrm{i}}$ denotes that an individual does not have a spouse who holds an employer-provided health insurance plan. The sample now only consists of wage and salaried workers in the baseline year ( $\mathrm{t}$ ) who hold employer-provided health insurance. The dependent variable equals 1 if the worker moves to self-employment in the following year $(t+1)$. We estimate this model with the remaining measures of potential health insurance demand. The coefficient on the interaction between no spouse health insurance and high health care demand, $\beta_{3}$, captures the difference-indifference estimate of the entrepreneurship-lock. A negative coefficient suggests that those individuals who would face a disruption in their health insurance and have a high demand for health care are relatively less likely to move into self-employment than individuals with a low demand for health care. ${ }^{19}$

To obtain even further compatibility between the experimental and control groups, we estimate several robustness checks in which the sample is restricted based on spousal characteristics. We impose two restrictions to the sample of individuals who hold employerprovided health insurance: (1) only married couples and (2) only spouses who are both working at least 30 hours per week.

Table 4A reports the results from estimating equation (6.1) for men using the full sample. Columns $1-3$ present three different measures of high health care demand, no spouse health insurance, anyone in the family in bad health, and number of family members in bad health. ${ }^{20}$ The estimates from the models in Table 4A show that whites and immigrants are more likely to become self-employed. Workers with relatively more education, with higher family incomes and

\footnotetext{
${ }^{19}$ We also estimated models including a control for the interaction between marital status and health, to explore the possibility that the interaction term between spouse health insurance and health may be capturing the effect of being married. These models generated similar results.

${ }^{20}$ We have also estimated the models with a measure of family health that includes the individual's own health. Results using this measure are quite similar to the results reported in the paper.
} 
home-owners are also more likely to start businesses. In general, these results are consistent with findings from the previous literature and the notion that workers with more resources are the most likely to be able to start a business. ${ }^{21}$

The direct effect of own employer provided health insurance on the control group is large - workers who have such health insurance are between 2.5 and 3.9 percentage points less likely to move to self employment relative to a baseline transition rate of 4 percent. However, we cannot place much weight on the direct effect of health insurance since it could be contaminated by unobserved job quality, and so we rely on the interaction of the high demand variables with employer health insurance (e.g. $\beta_{3}$ ) to determine if insured individuals with a high demand for health care are relatively less likely to become entrepreneurs compared to individuals with a low demand for health care.

In column 1, the interaction of employer health insurance and no spouse health insurance is negative and statistically significant. The magnitude of the estimated effect is 2 percentage points which is quite large relative to a base entrepreneurship transition rate of 4 percent suggesting that the lack of spouse health insurance is a disincentive to entrepreneurship for those who rely on their own employer policy. For the other measures of potential demand for health insurance in columns 2 and 3, the results are not as clear. The coefficients on the interactions between own employer health insurance and anyone with bad health and own employer health insurance and the number of family members with bad health are both positive, but statistically insignificant.

The results for women in table 4B are somewhat similar. Employer provided health insurance has a large negative direct effect on transitions for the control group. It appears that higher wage women are also less likely to move to self-employment -- the effects of wage and health insurance are similar for women, unlike for men. Similar to the results for men, the

\footnotetext{
${ }^{21}$ See Parker (2004) and Fairlie and Robb (2008) for recent reviews of the literature on the determinants of business ownership.
} 
coefficient on the interaction between own employer health insurance and no spouse employer insurance is negative and statistically significant. The coefficient estimate is also large implying an effect of 1.75 percentage points. Using the alternative measures for potential demand, we do not find negative coefficients on the interaction terms.

The estimates reported in Tables 4A and 4B provide some support for the hypothesis that employer-based health insurance limits entrepreneurship, but the evidence is not consistent across different measures of health demand. As noted above, a potential problem with this approach is that we are defining the experimental group as individuals who have their own employer health insurance and the control group as individuals who do not have their own employer health insurance. Although these estimates may be suggestive, the comparability of these two groups is in question. To address these concerns, we restrict the sample to only workers who have their own employer health insurance and estimate equation (6.2).

Table 5A reports the results for men. We report the main effects and interactions between not having a spouse with employer health insurance and the two remaining health demand measures in Columns 1-2. The experimental group is defined as individuals who do not have spouses with employer health insurance and the control group is defined as individuals who have spouses with employer health insurance. The coefficient on the interaction between no spouse health insurance and anyone in bad health in the family is large, negative and statistically significant. The coefficient estimates on the number of family members in bad health is also negative and statistically significant. These estimates show that men with poor family health and no spouse health insurance are significantly less likely to give up their employer plan and move to self employment.

The results are similar for women (Table 5.B). Female workers in families with poor health and do not have spouses with health insurance are less likely to start businesses. For both measures of poor family health the coefficients are large, negative and statistically significant. 


\section{ADDITIONAL ESTIMATES}

A concern with the specifications columns 1 and 2 of tables $5 \mathrm{~A}$ and $5 \mathrm{~B}$ is that the experimental group includes both married and unmarried workers whereas the control group only includes married workers in dual-worker couples because this group has a spouse with employer health insurance. To further improve the comparability of the experimental and control groups we first limit the sample to married workers. We find that these results are similar to the ones reported in columns 1 and 2 of Tables 5A and 5B. To further increase comparability, we limit the sample to married couples with full-time, full-year working spouses (estimates are reported in columns 3 and 4 of Tables 5A and 5B). We find that the interaction between the health measures and spousal health insurance strengthens in magnitude slightly and continues to be statistically significant. However, for women, the interaction term becomes somewhat smaller in magnitude and statistically insignificant.

The results from the difference-in-difference models have their limitations. The estimates assume that the family health variables are adequate proxies for health care demand. In addition, the models estimated on the sample of the insured, assume that spousal health insurance is exogenous to the move to entrepreneurship. We have no credible way of relaxing this assumption. However, the regression discontinuity estimates presented in the next section do not hinge on this assumption, and provide an alternative estimation strategy.

\section{REGRESSION DISCONTINUITY DESIGN ESTIMATES}

We take a new approach to examine the question of whether health insurance discourages entrepreneurship by exploiting the discontinuity created at age 65 through the qualification for Medicare. In the month that individuals turn 65 they automatically qualify for Medicare, 
changing their access to health insurance coverage. ${ }^{22}$ Card, Dobkin, and Maestas $(2004,2008)$ show that health insurance coverage increases substantially at age 65. Attaining Medicare eligibility should immediately reduce the value an individual places on employer-sponsored health insurance. In particular, would-be-entrepreneurs no longer have to be concerned about losing basic employer-sponsored health insurance coverage after that date. We can isolate the effects of the "Medicare notch" by comparing self-employment rates just before the age 65 birth month to just after the age 65 birth month. This approach addresses additional concerns over the potential influence of unobservables such as health insurance preferences and individual health status, on the results. The main criticism is that it provides only a local estimate of the effect of health insurance on self-employed business ownership for older workers.

To take this approach we use matched monthly data from the CPS. ${ }^{23}$ By matching consecutive months of the CPS, we can identify the exact month in which the person's age in years changes. The CPS interviews households for 4 consecutive months, which allows us identify up to two months before the birth month, the birth month, and 2 months after the birth month. We cannot, however, identify the birth month of individuals whose birth month does not fall in the four month interview window. To our knowledge, this approach of using matched monthly CPS data has not been previously used to estimate regression discontinuity models. The approach is useful for identifying whether "entrepreneurship lock" exists. Few data sets contain a large enough sample size as well as information needed to identify exact birth month. The approach also has an advantage over many previous regression discontinuity studies that rely on age in years or quarters because we do not have to make potentially strong assumptions about the shape of the relationship between age and the outcome. The effects of age on entrepreneurship will be small because we can sharpen the focus around the age 65 birth month.

\footnotetext{
${ }^{22}$ Individuals automatically qualify for Medicare Part A (hospital insurance) in the month they turn age 65 if they have 40 quarters of previously covered employment or have a qualifying spouse. Medicare Part B (insurance) can be purchased for a small monthly payment.

${ }^{23}$ A limitation of the basic monthly CPS data is that we have no information on health insurance coverage or health status. We thus cannot distinguish individuals by demand for health insurance or care.
} 
We first examine business ownership rates by age in years. Figure 1 reports estimates for men between the ages of 25 and 75 in the workforce. There is a clear jump at age 65 in business ownership rates. We find that the percentage of workforce that owns a business increases from 26.5 percent at age 64 to 28.7 percent at age $65 .{ }^{24}$ Although we do not focus on women, we also find a large increase in business ownership rates at age 65 . We do not focus on women in this analysis because the use of data from the 1996 to 2006 CPS implies that individuals who reach age 65 in the sample were born in the 1930s. There have been dramatic changes in labor force participation among women belonging to this cohort (Lichter and Costanszo, 1987; McEwen, Orrenius and Wynne, 2005). In addition, this age group has too low of a labor force participation rate. We find that only around 30 percent of women ages 55-75 are employed. We thus only examine self-employment for men in this section.

In this analysis we focus primarily on changes in the self-employed business ownership rate at age 65 . Unlike the previous section, we cannot model annual transition rates into selfemployment because our empirical strategy requires us to compare consecutive months around the age 65 birth month. Although we can examine monthly transitions into self-employment, it is difficult to detect any statistically significant changes because the baseline monthly transition rate is extremely small at $0.004{ }^{25}$ We explore this issue further below in checking the robustness of the results. We find roughly similar-sized point estimates.

Estimates of self-employment rates by age in years indicate an increase in selfemployment at age 65 , but there is a lot of variation by age. ${ }^{26}$ Because of this variation we focus the analysis around the month of the $65^{\text {th }}$ birthday when individuals become eligible for

\footnotetext{
${ }^{24} \mathrm{We}$ also find a large increase in self-employment rates at age 65 using the 2000 Census, but we cannot identify age in months in these data.

${ }^{25}$ The difficulty of identifying statistically significant changes in very small proportions has been noted previously (see Cohen 1988 for example). A simple comparison of t-statistics for the test of $10 \%$ changes in the monthly transition rate into self-employment and the self-employment rate, which is 0.23 reveals that a roughly 10 times larger sample size is needed to find a statistically significant change in the monthly transition rate.

${ }^{26}$ There also appears to be a large increase in self-employment rates at age 62, but when we focus in around the age 62 month we do not find evidence of a break in self-employment rates.
} 
Medicare. To compare individuals on either side of their birth month we limit the sample to workers whose birth month falls in the four consecutive month interview period. We create three groups: the two months before a birth month (just under age 65), the month in which the age changes (almost age 65), and the two months following an age change (just over age 65). The "almost age 65 " category is created because of the ambiguity over whether the individual's birthday is in the same calendar month as the survey month or if it falls in the calendar month after the survey month. The survey date is typically in the second week of the month.

Figure 2 reports estimates of self-employment rates around the age 65 cutoff. There is a clear break at age 65 . Business ownership rates increase from 24.6 percent for those just under age 65 to 28.0 percent for those just over age 65 . The difference is statistically significant. We also find that the business ownership rates increase from the just before age 65 category to the almost age 65 category, which is consistent with an increase in rates in the month individuals turn age 65 . Some individuals in the almost age 65 group will have turned age 65 by the survey date. As reflected in Figure 1, the rate of business ownership increases with age. Therefore, it is possible, if unlikely, that the large increase in business ownership rates from 1-2 months before turning 65 to 1-2 months after turning 65 is due to the slight increase in age. For this reason, we examine whether business ownership rates increase from just before to just after changes in other ages. As a first pass at exploring this question, Figure 3 reports estimates for the three categories for all other ages 55 to 75 . As expected, because age is only increasing slightly from just before to just after the birth month the business ownership rates are essentially the same around the birth month cutoff. For these age changes, there is no change in eligibility for health insurance. We next examine changes in rates from just before to just after for each age in years and only found two ages with statistically significant changes other than the age 65 break. ${ }^{27}$ Neither of these, however, was as large as the age 65 break. Note that given the 20 tests conducted, we expect to find a couple of statistically significant differences simply by chance.

\footnotetext{
${ }^{27}$ The other breaks occur at age 59 and 61 .
} 
The discontinuity at age 65 can also be seen from a plot of business ownership rates before and after the cutoff using our sample of workers with birth months falling in the fourmonth window of the CPS (see Figure 4). Separate linear predictions on either side of the discontinuity indicate a break in business ownership rates at age 65 . The predicted difference in rates is similar in magnitude to the actual break in rates from just before to just after turning age 65.

To further investigate the discontinuity at age 65 , we estimate regressions in which we control for demographic characteristics and other factors. We start with a simple regression for the probability of business ownership among workers who are just under or just over age 65 . We model the probability of entrepreneurship as:

\section{3 $\operatorname{Prob}\left(\mathrm{y}_{\mathrm{it}}\right)=\Phi\left(\alpha+\lambda_{\mathrm{t}}+\delta_{1} \mathrm{D}_{\mathrm{i}}^{65 \mathrm{a}}+\delta_{2} \mathrm{D}_{\mathrm{i}}^{650}+\beta^{\prime} \mathrm{X}_{\mathrm{i}}\right)$,}

where $\lambda_{t}$ are year fixed effects, $D_{i}^{65 a}$ is a dummy for almost being age $65, D_{i}^{650}$ is a dummy for being just over age 65 , and $X_{i}$ is a vector of demographic controls. The omitted group is just under age 65 . Identification of the Medicare effect, $\delta_{2}$, is being driven entirely by comparing the just over age 65 group to the just under age 65 group. Because we have data on age in months and we can zero in around the age 65 cutoff, it is unlikely that any of the additional specifications discussed below will change the conclusions drawn on "entrepreneurship lock" from this regression specification.

To increase precision and control for potential effects of the small change in age from the just under to the just over categories, we also estimate regression discontinuity models. In this case, the probability of entrepreneurship is:

6.4 $\operatorname{Prob}\left(\mathrm{y}_{\mathrm{it}}\right)=\Phi\left(\alpha+\lambda_{\mathrm{t}}+\mathrm{g}\left(\mathrm{a}_{\mathrm{i}}\right)+\delta_{1} \mathrm{D}_{\mathrm{i}}{ }^{65 \mathrm{a}}+\delta_{2} \mathrm{D}_{\mathrm{i}}{ }^{650}+\delta_{3} \mathrm{D}_{\mathrm{i}}^{\mathrm{a}}+\delta_{4} \mathrm{D}_{\mathrm{i}}{ }^{\mathrm{o}}+\beta^{\prime} \mathrm{X}_{\mathrm{i}}\right)$, 
where $g(a)$ is a function of age in months, $D_{i}^{a}$ is the almost age dummy for all age groups, and $D_{i}{ }^{\circ}$ is the just over dummy for all age groups. ${ }^{28}$ The omitted group is just under age 65 . By including the just over dummy for all ages we capture the effects of the small change in age associated with being just over to just under a specific age. We also estimate regressions with two general forms for g(a). First, we estimate a standard quadratic form for age. Second, we estimate a very flexible form for $\mathrm{g}(\mathrm{a})$ that includes age in year fixed effects instead of a smooth function. This model is more flexible than most regression discontinuity models because it allows the pre and post age 65 levels to vary fully by age in years.

Table 6 reports estimates from several regressions of equation (6.3). The first specification includes only the age 65 cutoff dummy variables. The left-out category is just under age 65 . The coefficient on the just over age 65 variable is positive and statistically significant. The coefficient on the almost age 65 variable is smaller, but statistically insignificant. We also include controls for race, nativity, education, marital status, region, urban status, industry and year in the remaining specifications. The coefficient estimate on the just over age 65 variable remains very similar attesting to the strength of the research design. The addition of the covariates has little effect on the estimated relationship between being just over the age 65 cutoff and business ownership.

In Table 7, we report estimates for equation (6.4). We now include observations for all workers ages 55 to 75 . The first specification includes only the age cutoff dummy variables. The left-out category is just under age 65 . The coefficient on the just over age 65 variable is positive and statistically significant. Although there is a strong positive association between entrepreneurship and age, the results are not being driven by the small increase in age from the just before period to the just after period. We are implicitly controlling for this increase in age by including dummy variables for almost at the age cutoff and just over the age cutoff for all ages. As expected, these coefficients are very small suggesting that the small change in age between

${ }^{28}$ We adjust the standard errors for clustering by age group. 
these two periods for ages other than 65 when individuals qualify for Medicare does not have an effect on self-employment rates. Nevertheless, we estimate additional specifications with further controls for age and other variables to check the robustness of the results. In Specification 2, we include a quadratic function for age in months. The coefficient estimate on just over age 65 remains large, positive and statistically significant.

In Specification 3, we replace the smooth function for age in months with a much more flexible form that includes dummies for each age in years. Even allowing for a fully flexible form for the age-self-employment relationship for before and after age 65 , the estimates remain similar. We find a 0.033 higher probability of owing a business each month if the person is just over age 65 than if the individual is just under age 65 . Finally, we also include controls for year, race, nativity, education, marital status, region, urban status, and industry. The coefficient estimate on the just over age 65 variable remains very similar providing further evidence on the credibility of the regression discontinuity design. The addition of the covariates has little effect on the estimated relationship between being just over the age 65 cutoff and business ownership. For this specification, the coefficient estimate implies a 0.031 higher probability of owing a business each month if the person is just over age 65 than if the individual is just under age $65 .{ }^{29}$ This increase represents 13 percent of the mean probability of self-employment.

The estimate is not sensitive to narrowing the age range to 60 to 70 year olds. Specification 1 of Table 8 reports estimates using a sample with this age range. The coefficient estimate on the just over age 65 variable remains large, positive and statistically significant.

One possible concern is that the change in the probability of self-employment observed in these results may be due to changes in composition of the labor force or due to transitions other than the move from wage/salaried work to full-time self employment. For instance, wage/salaried workers may be moving to part-time self employment age 65 as part of their transition to

\footnotetext{
${ }^{29}$ Including dummy variables for other age breaks we only find significant coefficients for age 59 and 61 , but both have smaller coefficients than the age 65 break. This is similar to the univariate results noted above.
} 
retirement. To determine if this is driving our results, we restrict the sample to include only fulltime workers (defined as working 30 or more hours per week). This restriction rules out the possibility that movement to part-time self-employment at age 65 is driving the results. As reported in Specification 2, the coefficient estimate is similar to the original one. Another possibility is that the stock of workers falls at age 65 , and therefore the number of self-employed workers as share of all workers appears to be increasing even though the number of selfemployed workers remains constant. To address this concern, we expand the sample to include individuals who are not working 15 or more hours per week. We now include all individuals ages 55-75 even if they are not in the labor force to ensure that the denominator is not affected by the size and composition of the labor force. The probability of self-employment for this sample is lower (11.0 percent) because of the inclusion of non-workers. Specification 3 of Table 8 reports estimates using this sample. We find a higher rate of business ownership associated with being just over the age 65 break. The point estimate implies that the business ownership rate is 0.013 higher, which represents 12 percent of the sample mean. The relative magnitude of the coefficient is similar to the coefficient estimate using the main sample of workers. Thus, the results do not appear sensitive to the treatment of non-employment and low hours work. We also estimated a regression in which hours worked was the dependent variable and found no change in hours worked around the age 65 cutoff. The coefficient estimate on the just over age 65 variable was very small and statistically insignificant.

To further investigate whether individuals are retiring or dropping out of the work force in the month they turned age 65, we estimate a model in which employment is the dependent variable. We find a small and statistically insignificant coefficient estimate on the just over age 65 variable. This finding is consistent with estimates reported in Card, Dobkin and Maestas (2004, 2008). They find that employment does not change in quarter individual's turn age 65 . They also do not find evidence of changes in marriage, family income and household moves at age 65 . 
We are concerned about other confounding factors that might lead to shifts in employment behavior at age 65 such as eligibility for Social Security or for pensions. Zissimopoulos and Karoly (forthcoming) find that among individuals over age 50, those who had experienced a pension cash-out were more likely to transition from wage and salary work to selfemployment. Social Security eligibility does not appear to generate shifts in employment behavior precisely at age 65. The minimum retirement age for full Social Security benefits was 65 for individuals born in 1937 or earlier (i.e., those reaching eligibility before 2003) and is gradually increasing for later birth cohorts to age 67 for those born after 1959. The earliest age of eligibility for Social Security benefits is 62 ; benefits received by individuals at that point are reduced (in an actuarial neutral way) relative to what would be received if one were to retire at the full retirement age. Data reveal that individuals are far more likely to begin claiming benefits at age 62 than at age 65. A majority of Americans (59 percent of women and 56 percent of men) receiving Social Security benefits for the first time in 2004 were age 62. A smaller fraction of those claiming benefits (17 percent of women and 23 percent of men) were age 65. (Munnell and Sass 2007). Similarly, age 65 does not appear to be a primary focal point for the accrual or availability of pension wealth. Under defined contribution retirement plans, pension wealth accrual does not vary substantially by age; pension wealth continues to increase as long as a person works. The critical age for individuals covered under defined contribution plans is 59.5 because at that age individuals can begin withdrawing from a 401(k) without penalty (Friedberg and Webb, 2003). Under defined benefit plans, pension wealth accrual peaks at the age of early retirement eligibility, which is well before age 65 . Pension wealth may continue to increase up to age 65 (Friedberg and Webb, 2003; Poterba, Venti and Weiss, 2001).

The final robustness check involves focusing on transitions from non-business ownership to business ownership. As noted above, we cannot examine annual transition rates into selfemployment similar to the analysis using the matched March CPS files because our empirical strategy requires us to compare consecutive months. Instead, we can only examine monthly 
transition rates which have a very low probability (sample average $=0.004$ ). Nevertheless, we estimate equation (6.4) using the monthly self-employment entry as the dependent variable as a robustness check. Specification 4 of Table 8 reports estimates. Similar to the previous results, we find a positive coefficient estimate on the just over age 65 variable. The coefficient, however, is not statistically significant. The point estimate implies that the entrepreneurship rate is 0.001 higher, which represents 29 percent of the sample mean. The magnitude of this coefficient estimate relative to the mean is larger, but roughly consistent with the finding for the just over age 65 variable in the self-employment rate specifications. ${ }^{30}$

\section{Conclusions}

A major concern with the U.S. focus on employer provided health insurance is that it might restrict business starts. The potential loss or disruption in health insurance coverage due to pre-existing condition limitations, waiting periods for coverage, changes in health plans and providers, high premiums in the individual health insurance market, and risk of high health costs while uninsured may dissuade many employees from starting a business when it would otherwise be optimal. The current debate on health care reform includes initiatives that would improve access to health insurance for the self-employed and employees of small businesses through a national, open-access plan.

Given these concerns it is surprising that only a handful of studies have examined whether employer-provided health insurance limits entrepreneurship, with the few studies in this literature finding mixed results. We address the limited research on the topic of "entrepreneurship lock" by providing a new study using panel data created by matching consecutive years or months of the CPS and two main identification strategies -- difference-indifference and regression discontinuity models.

\footnotetext{
${ }^{30}$ We also estimated a regression for the monthly probability of exiting from self-employment and found a very small and statistically insignificant coefficient estimate on the just over age 65 variable.
} 
A first pass at the data reveals that the self-employed are much less likely to have health insurance than are wage/salary workers and even our sample of unemployed and part-time workers. Estimates from our two-year panel data from matching consecutive March CPS files also indicate that new self-employment entrants have especially low rates of health insurance coverage. We also find that business creation rates are substantially lower among wage/salary workers who have employer insurance than among wage/salary workers who have insurance coverage through a spouse or do not have insurance.

To address concerns that workers who have employer-provided health insurance may be less likely to move to self-employment simply because they already have a job with a good compensation package and high job quality, we first estimate difference-in-difference models. Identification of "entrepreneurship lock" arises from the interaction between having employerprovided health insurance and potential demand for health care. Using this first approach, we find some evidence that employer-based health insurance limits entrepreneurship, especially for men, but the evidence is not consistent across different measures of potential demand for health care. To improve the comparability of the experimental and control groups, we limit the sample to only individuals who have employer-based health insurance. Identification then comes from the interaction between having a spouse with employer-based health insurance and potential demand for health care. For men, we find consistent evidence of a larger negative effect of health insurance demand on the entrepreneurship probability for those without spousal coverage than for those with spousal coverage. Several robustness checks that further refine the comparability between experimental and controls groups provide similar results. Our estimates suggest that entrepreneurship lock for men is just over 1 percentage point relative to a base transition rate of 3 percent. We also find evidence of entrepreneurship lock for women, however, the coefficients are not precisely estimated in a couple of specifications.

We also take a new approach in the literature to examining the question of whether employer-based health insurance discourages entrepreneurship by examining the discontinuity 
created at age 65 through the qualification for Medicare. Using a novel procedure of identifying age in months from matched monthly CPS data, we compare the probability of business ownership among male workers in the months just before turning age 65 and in the months just after turning age 65 . Business ownership rates increase from 24.6 percent for those just under age 65 to 28.0 percent for those just over age 65 , whereas we find no change in business ownership rates from just before to just after for the remaining ages in our sample of workers ages 55-75. We estimate several regression discontinuity models to confirm these results. As expected because of the small change in actual age and the orthogonality of included controls, we find a similarly large and statistically significant increase in self-employment rates in the age 65 birth month when the worker qualifies for Medicare. These results are not sensitive to several alternative samples, dependent variables, and age functions. Using different empirical methodologies and samples, the difference-in-difference and the regression discontinuity models both suggest that health insurance reduces entrepreneurship.

Overall we find some evidence that the U.S. emphasis on employer-provided health insurance may be limiting entrepreneurship. The clearest evidence comes from the regression discontinuity results which create the most comparability in experimental and controls groups. The finding of "entrepreneurship lock" is important as it suggests that the bundling of health insurance and employment may create an inefficient allocation of which or when workers start businesses. 


\section{References}

Ai, C. and E.C. Norton (2003). "Interaction Terms in Logit and Probit Model," Economic Letters, 80, pp. 123-129

AWP Research (2005). 2005 Health Care Survey. Final Report. Prepared for the National Assocation of the Self-Employed.

Bennefield, Robert L. 1996. "A Comparative Analysis of Health Insurance Coverage Estimates: Data from CPS and SIPP," Paper presented at the Joint Statistical Meetings, American Statistical Association.

Bhandari, Shailesh. 2004. "People with Health Insurance: A Comparison of Estimates from Two Surveys," The Survey of Income and Program Participation, U.S. Census Bureau Working Paper No. 243.

Baumol, William \& Robert Litan \& Carl Schramm (2007). "Sustaining Entrepreneurial Capitalism," Capitalism and Society, Berkeley Electronic Press, vol. 2(2).

Bernard, D. and J. Banthin (2008). "Premiums in the Individual Health Insurance Market for Policyholders under Age 65: 2002 and 2005. Statistical Brief \#202". April 2008. Agency for Healthcare Research and Quality, Rockville, MD. Available on -line:

http://www.meps.ahrq.gov/mepsweb/data files/publications/st202/stat202.pdf (As of October 24, 2008).

Birch, David (1979). The Job Creation Process, Cambridge, MA: Center for the Study of Neighborhood and Regional Change, Cambridge: MIT Press.

Bradford, William D (2003). "The Wealth Dynamics of Entrepreneurship for Black and White Families in the U.S.," Review of Income and Wealth, 49(1): 89-116.

Bucks, Brian K., Arthur B. Kennickell, and Kevin B.Moore (2006). "Recent Changes in U.S. Family Finances: Evidence from the 2001 and 2004 Survey of Consumer Finances," Federal Reserve Bulletin, Washington, D.C.: Board of Governors of the Federal Reserve System.

Card, David, Carlos Dobkin, and Nicole Maestas (2004). "The Impact of Health Insurance Status on Treatment Intensity and Health Outcomes." NBER Working Paper No. 10365.

Card, David, Carlos Dobkin, and Nicole Maestas (2008). "The Impact of Health Insurance Status on Treatment Intensity and Health Outcomes." American Economic Review 98(5): 2242-58.

Cohen, Jacob. (1988). Statistical Power Analysis for the Behavioral Sciences. Hillsdale, NJ: Lawrence Erlbaum Associates, Inc.

Congressional Budget Office. 2003. How Many People Lack Health Insurance and For How Long? Washington, DC: Congressional Budget Office.

Council of Economic Advisers. 2009. The Economic Case for Health Care Reform, Washington, D.C.: Executive Office of the President, Council of Economic Advisors, June 2009, http://www.whitehouse.gov/assets/documents/CEA_Health_Care_Report.pdf 
DeCicca, Philip (2007)." Health Insurance Availability and Entrepreneurship: Evidence from New Jersey". 2007 ERIU Summer Research Conference in Ann Arbor.

Egerstrom, Lee (2007). "Health Insurance: The Big Bump in the Road to Entrepreneurship." Twin Cities Daily Planet. http://www.tcdailyplanet.net/article/2007/08/28/health-insurance-bigbump-road-entrepreneurship.html\#

Fairlie, Robert W., and Rebecca A. London. 2008. "The Dynamics of Health Insurance Coverage: Identifying Trigger Events for Insurance Loss and Gain," (with Rebecca London), Health Services and Outcomes Research Methodology, (forthcoming).

Fairlie, Robert W., and Alicia M. Robb. 2008. Race and Entrepreneurial Success: Black-, Asian-, and White-Owned Businesses in the United States, Cambridge: MIT Press.

Friedberg, Leora and Webb, Anthony (2003). "Retirement and the Evolution of Pension Structure". NBER Working Paper No. W9999. Available at SSRN: http://ssrn.com/abstract=450900.

Gilleskie Donna B; Lutz Byron (2002). "The Impact of Employer-Provided Health Insurance on Dynamic Employment Transitions," Journal of Human Resources, 37: 129-162.

Gruber, Jonathan and Brigitte C. Madrian (2004). "Health Insurance, Labor Supply and Job Mobility: A Critical Review of the Literature," in Catherine G. McLaughlin, ed., Health Policy and the Uninsured (Urban Institute Press: Washington, DC) 97-178.

Gumus and Regan (2008). "Tax Incentives as a Solution to the Uninsured:

Evidence from the Self-Employed”. unpublished paper, October.

Holtz-Eakin, Douglas, John R. Penrod, and Harvey S. Rosen (1996). "Health Insurance and the Supply of Entrepreneurs," Journal of Public Economics 62(1-2): 209-235.

Kapur, Kanika (1998). "The Impact of Health on Job Mobility: A Measure of Job Lock," Industrial and Labor Relations Review 51(2): 282-297.

Keen, Judy (2005). "Health Insurance Costs May Kill New-Business Dreams”. Daily News Central. http://health.dailynewscentral.com/content/view/0001533/39/

Lichter, Daniel and and Janice Costanzo. (1987). "How Do Demographic Changes Affect Labor Force Participation of Women?" Monthly Labor Review, Vol. 110, No. 11. November, pp. 23-25. Available on-line at: http://www.bls.gov/opub/mlr/1987/11/rpt2full.pdf (as of August 18, 2008).

McEwen, Helen, Pia Orrenius and Mark Wynne (2005). "Opting Out of Work: What's Behind the Decline in Labor Force Participation?" Southwest Economy, Issue 6, November, December. Available on-line at: http://www.dallasfed.org/research/swe/2005/swe0506a.html (as of August 18, 2008).

Madrian, Brigitte C. and Lars John Lefgren (1998). "The Effect of Health Insurance on Transitions to Self Employment," unpublished paper (University of Chicago). 
Meyer, Bruce D. (1995). "Natural and Quasi-experiments in Economics," Journal of Business \& Economic Statistics, American Statistical Association, vol. 13(2), pages 151-61, April.

Munnell, Alicia H. and Steven A. Sass (2007). "The Labor Supply of Older Americans". Center for Retirement Research at Boston College, CRR-WP 2007-12. Available on-line:

http://crr.bc.edu/images/stories/Working_Papers/wp_2007-

12.pdf?phpMyAdmin=43ac483c4de9t51d9eb41 (as of October 24, 2008).

National Federation of Independent Business (2008). "Small Business Problems and Priorities." http://www.nfib.com.

OECD (2005). SME and Entrepreneurship Outlook - 2005 Edition, Organisation for Economic Co-operation and Development Press.

Okunade Albert A; Wunnava Phanindra V. (2002). "Availability of Health Insurance and Gender Differences in 'Job-Lock' Behavior: Evidence from NLSY," Journal of Forensic Economics, 15: 195-204.

Parker, Simon C. (2004). The Economics of Self-Employment and Entrepreneurship. Cambridge: Cambridge University Press.

Poterba, James M., Venti, Steven F. and Wise, David A. (2001). "The Transition to Personal Accounts and Increasing Retirement Wealth: Macro and Micro Evidence". NBER Working Paper No. W8610. Available at SSRN: http://ssrn.com/abstract=291285.

Reynolds, Paul (2006). Entrepreneurship in the US: The Future is Now. New York: Springer.

Sanz de Galdeano Anna (2006). “Job-Lock and Public Policy: Evidence from Clinton's Second Mandate," Industrial and Labor Relations Review, 59: 430-437.

Stroupe Kevin T; Kinney Eleanor D., Kniesner Thomas J. (2001). "Chronic Illness and Health Insurance-Related Job Lock,” Journal of Policy Analysis and Management, 20: 525-44.

Swartz, Katherine. (1986) "Interpreting the Estimates from Four National Surveys of the Number of People without Health Insurance," Journal of Economic and Social Measurement, 14: 233-242.

U.S. Census Bureau. (1997) 1992 Economic Census: Characteristics of Business Owners. Washington, D.C.: U.S. Government Printing Office.

U.S. Census Bureau (2007). Current Population Survey. http://www.census.gov/cps/

Velamuri (2005). Taxes, Health Insurance and Women's Self-Employment, Working Paper.

Wellington, N. J., "Health Insurance Coverage and Entrepreneurship" (October 2001). Contemporary Economic Policy, Vol. 19, Issue 4, pp. 465-478, 2001 Available at SSRN: http://ssrn.com/abstract $=904703$

Zissimopoulos, Julie and Lynn Karoly (Forthcoming). "Labor Force Dynamics at Older Ages: Movements in Self-employment for Workers and Nonworkers" in Research on 
Aging. Available electronically at:

http://roa.sagepub.com/cgi/rapidpdf/0164027508324642v1 (October, 2008).

Zissimopoulos, J. and L, Karoly (2007). "Transitions to Self-Employment at Older Ages: The Role of Wealth, Health, Health Insurance and Other Factors". Labour Economics: 14 269-295. 
Figure 1

Business Ownership Rates by Age, Current Population Survey 1996-2006

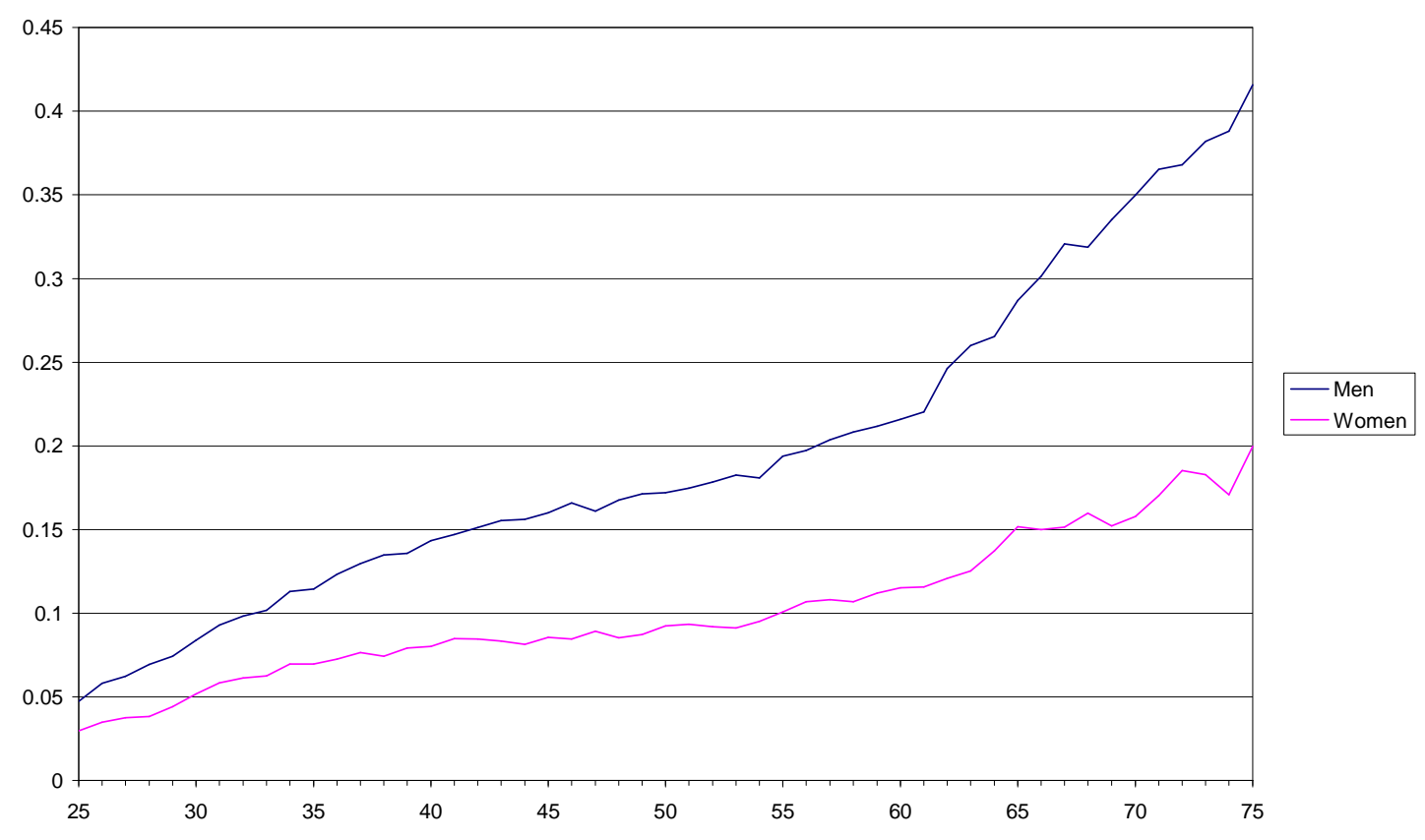


Figure 2

Self-Employment Rates around Age Cutoffs (Ages 65), Men Matched Current Population Surveys (CPS), 1996-2006

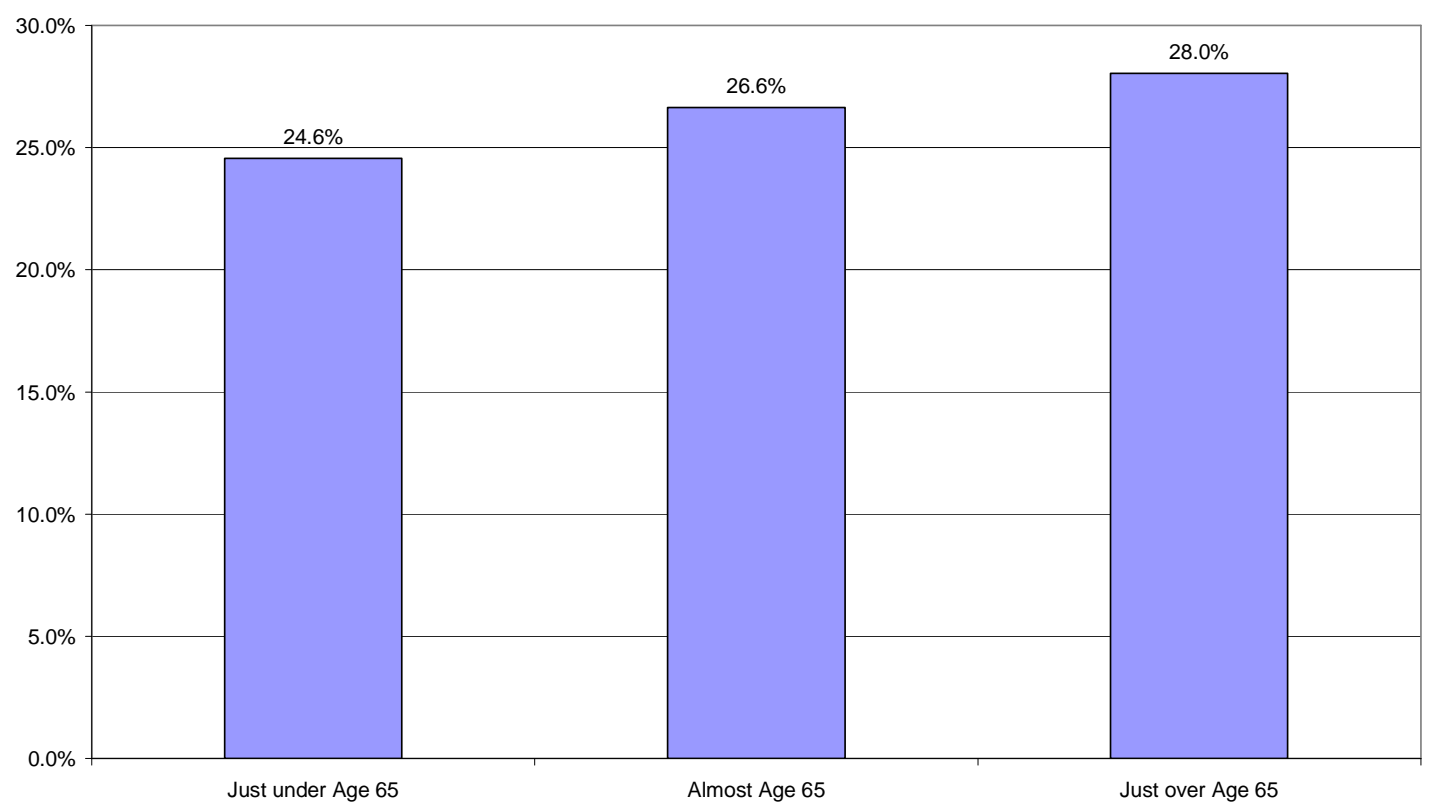


Figure 3

Self-Employment Rates around Age Cutoffs (Ages 55-64, 66-75), Men Matched Current Population Surveys (CPS), 1996-2006

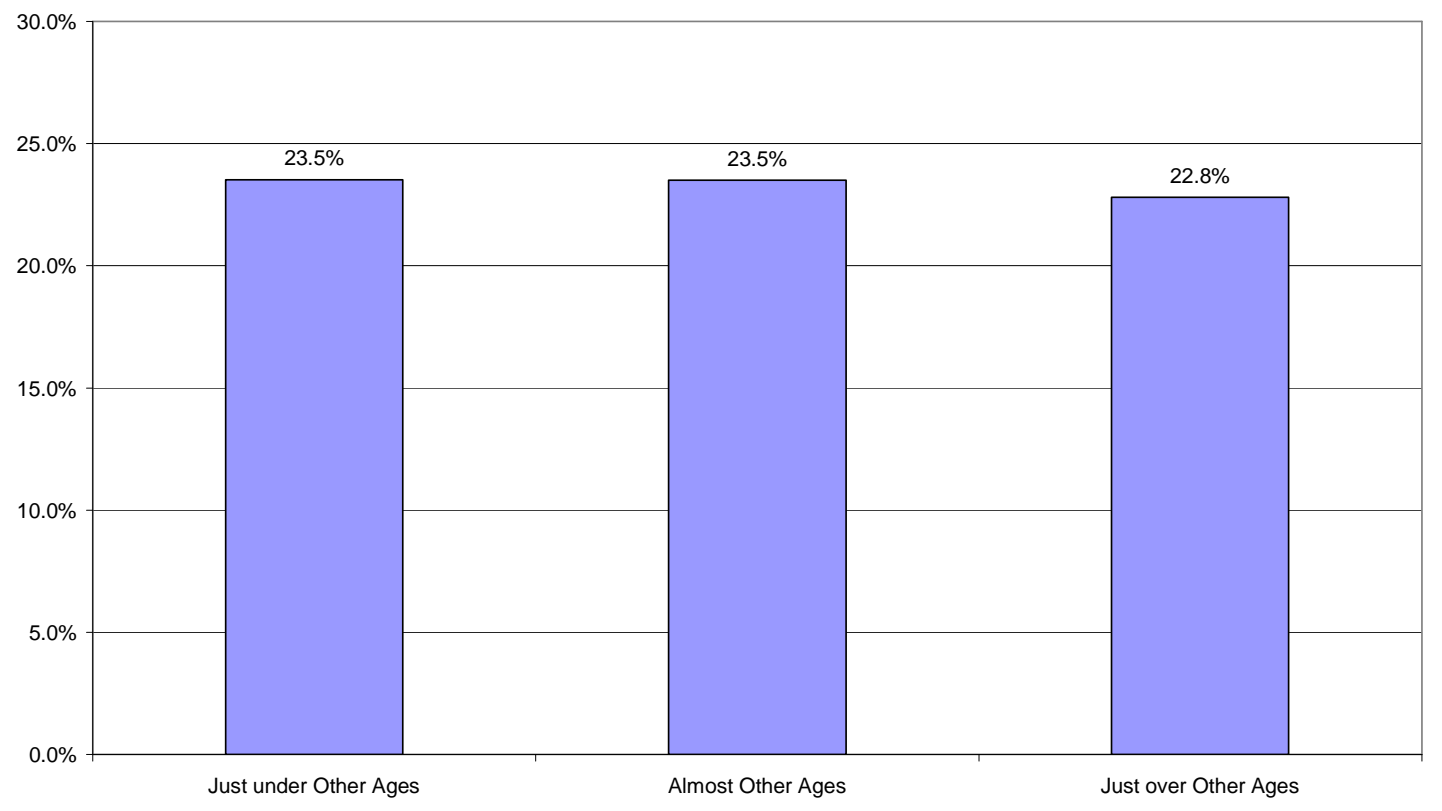


Figure 4

Self-Employment Rates by Age, Men

Matched Current Population Surveys (CPS), 1996-2006

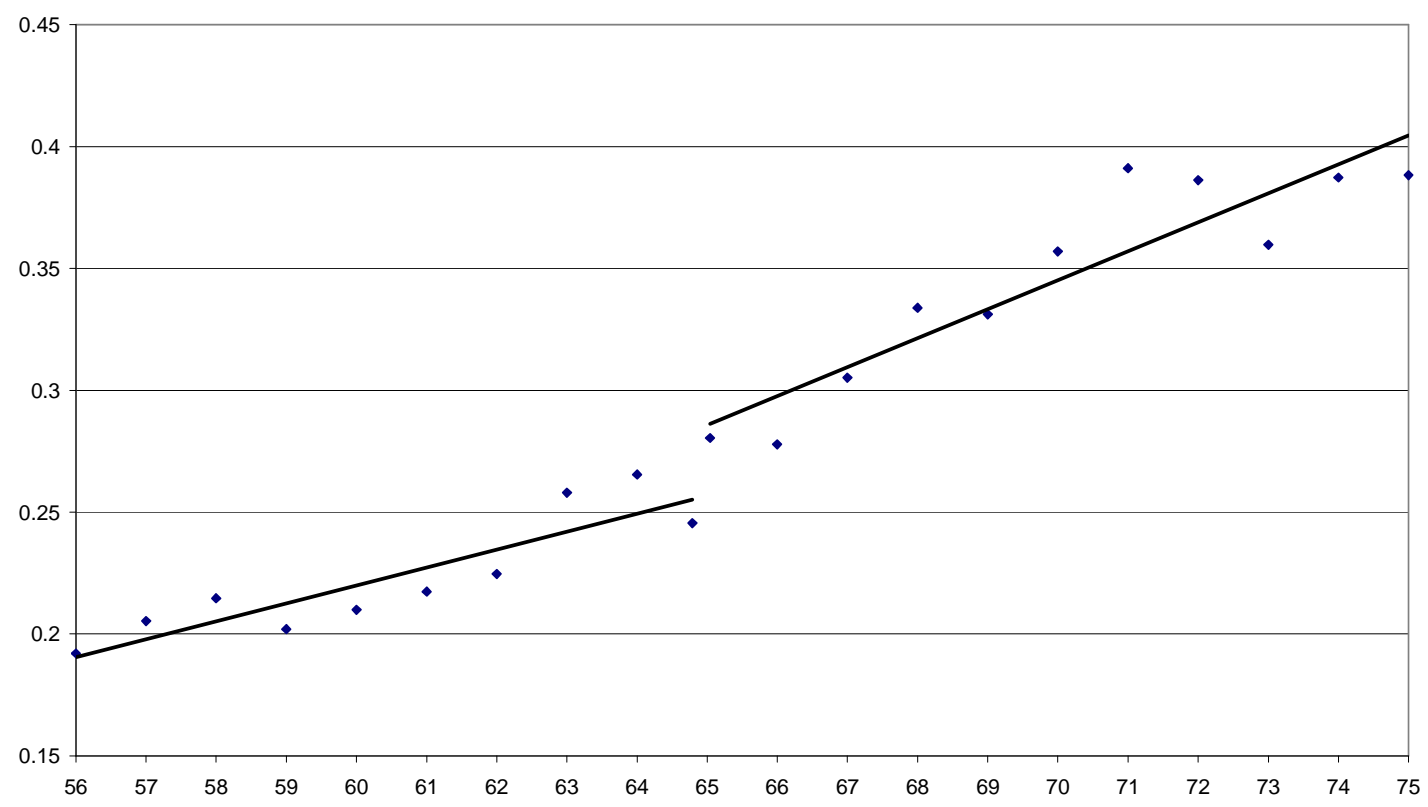

40 
Table 1

Insurance Type by Class of Worker

Matched Current Population Surveys (1996-2006)

Employer

Uninsured Employer Dependent Individual Medicaid Medicare Other N

\begin{tabular}{lcccccccc}
\hline Men & & & & & & & & \\
$\quad$ Self-Employed & $20.8 \%$ & $32.7 \%$ & $21.1 \%$ & $21.0 \%$ & $1.0 \%$ & $1.8 \%$ & $1.5 \%$ & 16,480 \\
Wage/Salary workers & $11.8 \%$ & $74.7 \%$ & $8.7 \%$ & $2.5 \%$ & $0.9 \%$ & $0.5 \%$ & $0.9 \%$ & 88,648 \\
Other/not working & $14.0 \%$ & $30.1 \%$ & $9.5 \%$ & $14.3 \%$ & $12.3 \%$ & $17.6 \%$ & $2.2 \%$ & 28,118 \\
Self-Employed (full-time) & $20.1 \%$ & $33.7 \%$ & $21.5 \%$ & $21.1 \%$ & $0.9 \%$ & $1.3 \%$ & $1.4 \%$ & 14,905 \\
Wage/Salary (full-time) & $10.8 \%$ & $77.1 \%$ & $8.4 \%$ & $2.1 \%$ & $0.6 \%$ & $0.3 \%$ & $0.8 \%$ & 81,560 \\
& & & & & & & & \\
Women & & & & & & & & \\
Self-Employed & $19.0 \%$ & $19.0 \%$ & $34.6 \%$ & $22.1 \%$ & $1.6 \%$ & $1.5 \%$ & $2.2 \%$ & 7,903 \\
Wage/Salary workers & $10.5 \%$ & $62.4 \%$ & $20.3 \%$ & $3.2 \%$ & $1.8 \%$ & $0.6 \%$ & $1.3 \%$ & 85,286 \\
Other/not working & $14.5 \%$ & $13.7 \%$ & $32.4 \%$ & $14.3 \%$ & $12.0 \%$ & $11.1 \%$ & $2.0 \%$ & 57,974 \\
Self-Employed (full-time) & $19.7 \%$ & $21.3 \%$ & $31.7 \%$ & $22.5 \%$ & $1.5 \%$ & $1.1 \%$ & $2.2 \%$ & 5,782 \\
Wage/Salary (full-time) & $9.4 \%$ & $69.0 \%$ & $16.7 \%$ & $2.4 \%$ & $1.1 \%$ & $0.3 \%$ & $1.1 \%$ & 69,725 \\
\hline
\end{tabular}

Notes: (1) The sample includes individuals ages 25-64. (2) Self-employed and wage/salary workers are defined as 20 or more weeks per year and 15 or more hours per week. Other/not working includes low hours workers and non-workers. (3) Full-time work is defined as 40 or more weeks per year and 30 or more hours per week. 
Table 2

Insurance Type by Self-Employment Activity

Matched Current Population Surveys (1996-2006)

\begin{tabular}{|c|c|c|c|c|c|c|c|c|}
\hline & Uninsured & Employer & $\begin{array}{l}\text { Employer } \\
\text { Dependent }\end{array}$ & Individual & Medicaid & Medicare & Other & $\mathrm{N}$ \\
\hline \multicolumn{9}{|l|}{ Men } \\
\hline Newly self-employed & $24.5 \%$ & $37.7 \%$ & $19.9 \%$ & $14.3 \%$ & $1.3 \%$ & $1.0 \%$ & $1.3 \%$ & 3,377 \\
\hline SE in both years & $18.6 \%$ & $31.8 \%$ & $22.8 \%$ & $22.7 \%$ & $0.9 \%$ & $1.6 \%$ & $1.5 \%$ & 11,742 \\
\hline Self-employed leavers & $18.9 \%$ & $53.6 \%$ & $13.7 \%$ & $10.7 \%$ & $0.9 \%$ & $1.4 \%$ & $0.8 \%$ & 3,460 \\
\hline \multicolumn{9}{|l|}{ Women } \\
\hline Newly self-employed & $23.2 \%$ & $24.4 \%$ & $31.4 \%$ & $15.6 \%$ & $2.1 \%$ & $0.9 \%$ & $2.4 \%$ & 1,803 \\
\hline SE in both years & $17.4 \%$ & $19.2 \%$ & $35.3 \%$ & $23.7 \%$ & $1.3 \%$ & $1.4 \%$ & $1.7 \%$ & 4,806 \\
\hline Self-employed leavers & $16.7 \%$ & $35.7 \%$ & $28.2 \%$ & $14.8 \%$ & $1.6 \%$ & $1.3 \%$ & $1.8 \%$ & 1,853 \\
\hline
\end{tabular}


Table 3

Self-Employment Transition Rates by Insurance Type Matched Current Population Surveys (1996-2006)

\begin{tabular}{lcccc} 
& $\begin{array}{c}\text { WS to SE } \\
\text { Entry Rate }\end{array}$ & $\mathrm{N}$ & $\begin{array}{c}\text { WS to SE } \\
\text { Entry Rate } \\
\text { (Full-Time) }\end{array}$ & $\mathrm{N}$ \\
\hline Men & $4.0 \%$ & 83,061 & $3.7 \%$ & 74,505 \\
$\quad$ Total & $2.9 \%$ & 63,149 & $2.7 \%$ & 58,571 \\
$\quad$ Employer insurance & $6.6 \%$ & 7,437 & $6.7 \%$ & 6,418 \\
$\quad$ Employer dependent insurance & $6.5 \%$ & 8,732 & $6.3 \%$ & 6,893 \\
$\quad$ No insurance & & & & \\
& & & & \\
Women & $2.3 \%$ & 77,065 & $1.9 \%$ & 60,181 \\
$\quad$ Total & $1.5 \%$ & 49,511 & $1.3 \%$ & 42,847 \\
$\quad$ Employer insurance & $3.2 \%$ & 15,366 & $2.9 \%$ & 9,799 \\
$\quad$ Employer dependent insurance & $3.7 \%$ & 7,216 & $3.3 \%$ & 4,852 \\
$\quad$ No insurance &
\end{tabular}

Notes: (1) The sample includes individuals ages $25-64$ who work 20 or more weeks and 15 or more hours per week in both survey years. All observations with allocated class of worker, weeks or hours information are excluded from the sample. (2) The full-time sample includes individuals ages 25-64 who work 20 or more weeks and 15 or more hours per week in both survey years. 
Table 4.A

Probit Regressions for Probability of Entrepreneurship for Men Matched Current Population Survey (1996-2006)

\begin{tabular}{|c|c|c|c|}
\hline Explanatory Variables & (1) & (2) & (3) \\
\hline Black & $\begin{array}{l}-0.0185 \\
(0.0033)\end{array}$ & $\begin{array}{l}-0.0180 \\
(0.0033)\end{array}$ & $\begin{array}{l}-0.0180 \\
(0.0033)\end{array}$ \\
\hline Latino & $\begin{array}{c}-0.0220 \\
(0.0034)\end{array}$ & $\begin{array}{l}-0.0206 \\
(0.0033)\end{array}$ & $\begin{array}{l}-0.0206 \\
(0.0033)\end{array}$ \\
\hline Asian & $\begin{array}{c}-0.0060 \\
(0.0041)\end{array}$ & $\begin{array}{l}-0.0058 \\
(0.0041)\end{array}$ & $\begin{array}{l}-0.0058 \\
(0.0041)\end{array}$ \\
\hline Immigrant & $\begin{array}{c}0.0119 \\
(0.0028)\end{array}$ & $\begin{array}{c}0.0127 \\
(0.0027)\end{array}$ & $\begin{array}{c}0.0127 \\
(0.0027)\end{array}$ \\
\hline Age & $\begin{array}{c}0.0019 \\
(0.0006)\end{array}$ & $\begin{array}{c}0.0018 \\
(0.0006)\end{array}$ & $\begin{array}{c}0.0018 \\
(0.0006)\end{array}$ \\
\hline Age squared & $\begin{array}{c}-0.0015 \\
(0.0007)\end{array}$ & $\begin{array}{l}-0.0015 \\
(0.0007)\end{array}$ & $\begin{array}{l}-0.0015 \\
(0.0007)\end{array}$ \\
\hline High school graduate & $\begin{array}{c}0.0073 \\
(0.0028)\end{array}$ & $\begin{array}{c}0.0062 \\
(0.0028)\end{array}$ & $\begin{array}{c}0.0062 \\
(0.0028)\end{array}$ \\
\hline Some college & $\begin{array}{c}0.0080 \\
(0.0029)\end{array}$ & $\begin{array}{c}0.0066 \\
(0.0029)\end{array}$ & $\begin{array}{c}0.0067 \\
(0.0029)\end{array}$ \\
\hline College graduate & $\begin{array}{c}0.0155 \\
(0.0031)\end{array}$ & $\begin{array}{c}0.0139 \\
(0.0031)\end{array}$ & $\begin{array}{c}0.0140 \\
(0.0031)\end{array}$ \\
\hline Graduate school & $\begin{array}{c}0.0215 \\
(0.0035)\end{array}$ & $\begin{array}{c}0.0203 \\
(0.0035)\end{array}$ & $\begin{array}{c}0.0204 \\
(0.0035)\end{array}$ \\
\hline Log wage & $\begin{array}{c}0.0039 \\
(0.0018)\end{array}$ & $\begin{array}{c}0.0044 \\
(0.0018)\end{array}$ & $\begin{array}{c}0.0044 \\
(0.0018)\end{array}$ \\
\hline Log family income & $\begin{array}{c}0.0053 \\
(0.0018)\end{array}$ & $\begin{array}{c}0.0037 \\
(0.0018)\end{array}$ & $\begin{array}{c}0.0037 \\
(0.0018)\end{array}$ \\
\hline Home ownership & $\begin{array}{c}0.0078 \\
(0.0020)\end{array}$ & $\begin{array}{c}0.0070 \\
(0.0020)\end{array}$ & $\begin{array}{c}0.0070 \\
(0.0020)\end{array}$ \\
\hline Own employer health insurance & $\begin{array}{c}-0.0253 \\
(0.0024)\end{array}$ & $\begin{array}{l}-0.0392 \\
(0.0016)\end{array}$ & $\begin{array}{c}-0.0392 \\
(0.0016)\end{array}$ \\
\hline No spouse employer health ins. & $\begin{array}{c}0.0211 \\
(0.0026)\end{array}$ & & \\
\hline Own employer $\mathrm{HI}^{*}$ no spouse emp. $\mathrm{HI}$ & $\begin{array}{c}-0.0244 \\
(0.0031)\end{array}$ & & \\
\hline Anyone in family in bad health & & $\begin{array}{l}-0.0045 \\
(0.0038)\end{array}$ & \\
\hline Own employer $\mathrm{HI}$ * anyone bad health & & $\begin{array}{l}-0.0003 \\
(0.0050)\end{array}$ & \\
\hline Number in family in bad health & & & $\begin{array}{l}-0.0025 \\
(0.0029)\end{array}$ \\
\hline Own employer $\mathrm{HI}^{*}$ number bad health & & & $\begin{array}{l}-0.0008 \\
(0.0040)\end{array}$ \\
\hline Mean of dependent variable & 0.0398 & 0.0398 & 0.0398 \\
\hline Sample size & 81,214 & 81,214 & 81,214 \\
\hline
\end{tabular}

Notes: (1) The dependent variable equals 1 if the individual switches from wage and salary work in survey year t to business ownership in survey year $t+1$. (2) Marginal effects and their standard errors are reported. (3) All specifications include controls for other race, multiple race, marital status, children, spousal employment, interest income, dividend income, rental income, region, urbanicity, industry and year of survey. 
Table 4.B

Probit Regressions for Probability of Entrepreneurship for Women Matched Current Population Survey (1996-2006)

\begin{tabular}{|c|c|c|c|}
\hline Explanatory Variables & (1) & (2) & (3) \\
\hline Black & $\begin{array}{c}-0.0071 \\
(0.0024)\end{array}$ & $\begin{array}{l}-0.0068 \\
(0.0024)\end{array}$ & $\begin{array}{l}-0.0068 \\
(0.0024)\end{array}$ \\
\hline Latino & $\begin{array}{c}-0.0057 \\
(0.0026)\end{array}$ & $\begin{array}{l}-0.0047 \\
(0.0026)\end{array}$ & $\begin{array}{l}-0.0047 \\
(0.0026)\end{array}$ \\
\hline Asian & $\begin{array}{c}-0.0031 \\
(0.0032)\end{array}$ & $\begin{array}{l}-0.0030 \\
(0.0032)\end{array}$ & $\begin{array}{l}-0.0030 \\
(0.0032)\end{array}$ \\
\hline Immigrant & $\begin{array}{c}0.0063 \\
(0.0022)\end{array}$ & $\begin{array}{c}0.0075 \\
(0.0022)\end{array}$ & $\begin{array}{c}0.0075 \\
(0.0022)\end{array}$ \\
\hline Age & $\begin{array}{c}0.0006 \\
(0.0005)\end{array}$ & $\begin{array}{c}0.0004 \\
(0.0005)\end{array}$ & $\begin{array}{c}0.0004 \\
(0.0005)\end{array}$ \\
\hline Age squared & $\begin{array}{c}-0.0004 \\
(0.0006)\end{array}$ & $\begin{array}{l}-0.0002 \\
(0.0006)\end{array}$ & $\begin{array}{l}-0.0002 \\
(0.0006)\end{array}$ \\
\hline High school graduate & $\begin{array}{c}0.0076 \\
(0.0026)\end{array}$ & $\begin{array}{c}0.0064 \\
(0.0026)\end{array}$ & $\begin{array}{c}0.0064 \\
(0.0026)\end{array}$ \\
\hline Some college & $\begin{array}{c}0.0116 \\
(0.0027)\end{array}$ & $\begin{array}{c}0.0102 \\
(0.0027)\end{array}$ & $\begin{array}{c}0.0102 \\
(0.0027)\end{array}$ \\
\hline College graduate & $\begin{array}{c}0.0164 \\
(0.0029)\end{array}$ & $\begin{array}{c}0.0152 \\
(0.0029)\end{array}$ & $\begin{array}{c}0.0151 \\
(0.0029)\end{array}$ \\
\hline Graduate school & $\begin{array}{c}0.0219 \\
(0.0032)\end{array}$ & $\begin{array}{c}0.0210 \\
(0.0032)\end{array}$ & $\begin{array}{c}0.0210 \\
(0.0032)\end{array}$ \\
\hline Log wage & $\begin{array}{c}-0.0025 \\
(0.0012)\end{array}$ & $\begin{array}{l}-0.0020 \\
(0.0013)\end{array}$ & $\begin{array}{l}-0.0020 \\
(0.0013)\end{array}$ \\
\hline Log family income & $\begin{array}{c}0.0055 \\
(0.0012)\end{array}$ & $\begin{array}{c}0.0035 \\
(0.0012)\end{array}$ & $\begin{array}{c}0.0035 \\
(0.0012)\end{array}$ \\
\hline Home ownership & $\begin{array}{c}0.0100 \\
(0.0017)\end{array}$ & $\begin{array}{c}0.0089 \\
(0.0017)\end{array}$ & $\begin{array}{c}0.0089 \\
(0.0017)\end{array}$ \\
\hline Own employer health insurance & $\begin{array}{c}-0.0126 \\
(0.0017)\end{array}$ & $\begin{array}{l}-0.0201 \\
(0.0012)\end{array}$ & $\begin{array}{c}-0.0202 \\
(0.0012)\end{array}$ \\
\hline No spouse employer health ins. & $\begin{array}{c}0.0196 \\
(0.0018)\end{array}$ & & \\
\hline Own employer $\mathrm{HI}^{*}$ no spouse emp. $\mathrm{HI}$ & $\begin{array}{c}-0.0175 \\
(0.0023)\end{array}$ & & \\
\hline Anyone in family in bad health & & $\begin{array}{c}0.0011 \\
(0.0026)\end{array}$ & \\
\hline Own employer $\mathrm{HI}$ * anyone bad health & & $\begin{array}{c}0.0033 \\
(0.0038)\end{array}$ & \\
\hline Number in family in bad health & & & $\begin{array}{c}0.0005 \\
(0.0021)\end{array}$ \\
\hline Own employer $\mathrm{HI}^{*}$ number bad health & & & $\begin{array}{c}0.0036 \\
(0.0031)\end{array}$ \\
\hline Mean of dependent variable & 0.0231 & 0.0231 & 0.0231 \\
\hline Sample size & 75,317 & 75,317 & 75,317 \\
\hline
\end{tabular}

Notes: (1) The dependent variable equals 1 if the individual switches from wage and salary work in survey year t to business ownership in survey year $t+1$. (2) Marginal effects and their standard errors are reported. (3) All specifications include controls for other race, multiple race, marital status, children, spousal employment, interest income, dividend income, rental income, region, urbanicity, industry and year of survey. 
Table 5.A

Probit Regressions for Probability of Entrepreneurship for Men who Have EPHI

Matched Current Population Survey (1996-2006)

Explanatory Variables

Sample restriction

No spouse employer health ins.

Anyone in family in bad health

No spouse employer $\mathrm{HI}^{*}$ anyone bad heal

Number in family in bad health

No spouse employer $\mathrm{HI}$ * number in bad health

Mean of dependent variable

Sample size
0.0290

62,060

(2)

(3)

Only EPH

Only EPHI

EPHI and
Spouse
Employed

Employed

$-0.0020$

(0.0018)

$-0.0009$

$(0.0021)$

0.0105

(0.0056)

(0.0049)

$-0.0134$

$(0.0057)$

$-0.0183$

(0.0083)

0.0073

$(0.0038)$

$-0.0141$

(0.0046)

0.0290

62,060
(4)

EPHI and

Spouse

ployed FT

$-0.0009$

(0.0021)

Notes: (1) The sample includes only individuals with own employer provided health insurance in Specifications 1 and 2. (2) The dependent variable equals 1 if the individual switches from wage and salary work in survey year $t$ to business ownership in survey year $t+1$. (3) Marginal effects and their standard errors are reported. (4) All specifications include controls for other race, multiple race, marital status, children, spousal employment, interest income, dividend income, rental income, region, urbanicity, industry and year of survey. 
Table 5.B

Probit Regressions for Probability of Entrepreneurship for Women who Have EPHI Matched Current Population Survey (1996-2006)

Explanatory Variables Sample restriction

No spouse employer health ins.

Anyone in family in bad health

No spouse employer $\mathrm{HI}^{*}$ anyone bad hea

Number in family in bad health

No spouse employer $\mathrm{HI}^{*}$ number in bad health

Mean of dependent variable

Sample size
(2)

Only EPHI

Only EPHI

Only EPH

$$
0.0011
$$

$-0.0119$

$(0.0038)$
(3)

(4)

Spouse $\quad$ SpHI and Employed FT Employed FT

$0.0006 \quad 0.0006$

$\begin{array}{ccc}0.0010 & 0.0006 & 0.0006 \\ (0.0014) & (0.0018) & (0.0018)\end{array}$

0.0105

$(0.0039)$

$-0.0086$

(0.0062)

0.0105

$(0.0031)$

$(0.0024)$

$-0.0092$

(0.0032)

0.0144

48,663
$-0.0072$

$(0.0052)$

0.0181

0.0181

23,917 23,917

Notes: (1) The sample includes only individuals with own employer provided health insurance in Specifications 1 and 2. (2) The dependent variable equals 1 if the individual switches from wage and salary work in survey year t to business ownership in survey year $t+1$. (3) Marginal effects and their standard errors are reported. (4) All specifications include controls for other race, multiple race, marital status, children, spousal employment, interest income, dividend income, rental income, region, urbanicity, industry and year of survey. 
Table 6

Probit Regressions for Probability of Business Ownership, Men around Age 65 Matched Current Population Surveys, 1996-2006

\begin{tabular}{lcccc} 
Explanatory Variables & $(1)$ & $(2)$ & $(3)$ & $(4)$ \\
\hline Almost at age 65 & 0.02112 & 0.01893 & 0.01998 & 0.01965 \\
& $(0.01668)$ & $(0.01623)$ & $(0.01591)$ & $(0.01523)$ \\
Just over age 65 & 0.03493 & 0.03280 & 0.03286 & 0.03029 \\
& $(0.01732)$ & $(0.01690)$ & $(0.01651)$ & $(0.01587)$ \\
Year fixed effects & No & No & No & Yes \\
Demographic controls & No & Yes & Yes & Yes \\
Industry controls & No & No & Yes & Yes \\
Mean of dependent variable & 0.26329 & 0.26329 & 0.26329 & 0.26329 \\
Sample size & 4,015 & 4,015 & 4,015 & 4,015 \\
\hline
\end{tabular}

Notes: (1) The sample consists of workers ages 65 with 15 or more hours worked per week. (2) Demographic controls include race, nativity, education, marital status, region, and urban status. 
Table 7

Probit Regressions for Probability of Business Ownership, Men Matched Current Population Surveys, 1996-2006

\begin{tabular}{lcccc} 
Explanatory Variables & $(1)$ & $(2)$ & $(3)$ & $(4)$ \\
\hline Almost at age cutoff & -0.00017 & -0.00148 & -0.00039 & 0.00000 \\
& $(0.00298)$ & $(0.00297)$ & $(0.00332)$ & $(0.00310)$ \\
Just over age cutoff & -0.00710 & -0.00219 & -0.00047 & -0.00110 \\
& $(0.00828)$ & $(0.00525)$ & $(0.00340)$ & $(0.00317)$ \\
Almost at age 65 & 0.02002 & 0.01982 & 0.01998 & 0.01637 \\
& $(0.00298)$ & $(0.00297)$ & $(0.01591)$ & $(0.01484)$ \\
Just over age 65 & 0.03992 & 0.03222 & 0.03286 & 0.03122 \\
& $(0.00828)$ & $(0.00527)$ & $(0.01651)$ & $(0.01537)$ \\
Age quadratic & No & Yes & No & No \\
Age in year dummies & No & No & Yes & Yes \\
Year fixed effects & No & No & No & Yes \\
Demographic controls & No & No & No & Yes \\
Industry controls & No & No & No & Yes \\
Mean of dependent variable & 0.23382 & 0.23382 & 0.23382 & 0.23382 \\
Sample size & 102,027 & 102,027 & 102,027 & 102,027 \\
\hline
\end{tabular}

Notes: (1) The sample consists of workers ages 55-75 with 15 or more hours worked per week. (2) Standard errors are adjusted for clustering by age in years. (3) Demographic controls include race, nativity, education, marital status, region, and urban status. 
Table 8

Probit Regressions for Probability of Business Ownership, Men, Additional Estimates Matched Current Population Surveys, 1996-2006

Explanatory Variables

(1)

(2)

(3)

(4)

Dependent Variable

SE Rate

SE Rate

SE Rate

SE Transition

Almost at age cutoff

$-0.00117$

$-0.00088$

0.00002

$-0.00010$

$(0.00507)$

$(0.00324)$

$(0.00151)$

$(0.00037)$

Just over age cutoff

$-0.00347$

0.00122

$-0.00043$

$-0.00011$

$(0.00525)$

(0.00331)

$(0.00155)$

(0.00038)

Almost at age 65

0.01921

0.01309

0.00727

0.00012

$(0.01622)$

$(0.01587)$

$(0.00706)$

$(0.00167)$

Just over age 65

0.03649

0.03525

0.01344

0.00116

Age in year dummies

(0.01681)

$(0.01640)$

(0.00726)

(0.00164)

Yes

Yes

Year fixed effects

Yes

Yes

Yes

Yes

Demographic controls

Yes

Industry controls

Yes

Yes

Yes

Yes

Yes

Yes

Yes

Yes

Yes

Mean of dependent variable

0.26019

0.22404

0.10992

0.00396

Sample size

43,797

91,083

215,052

183,871

Notes: (1) The sample consists of workers ages 60-70 in Specification 1, full-time workers ages 55-75 in Specification 2, and all individuals ages 55-75 in Specification 3, and non-business owners ages 55-75 in Specification 4. (2) Demographic controls include race, nativity, education, marital status, region, and urban status. 